\title{
Magnetohydrodynamic convection behaviours of nanofluids in non-square enclosures: A comprehensive review
}

\author{
S.O. Giwa ${ }^{1}$, M. Sharifpur ${ }^{1}$, Mohammad Hossein Ahmadi², and Josua Petrus Meyer ${ }^{1}$ \\ ${ }^{1}$ University of Pretoria \\ ${ }^{2}$ Shahrood University of Technology
}

May 5, 2020

\begin{abstract}
Nanofluid as a special thermal transporting medium has recently received unprecedented attention due to its improved heat transfer performance compared to conventional fluids. Numerous researches have been conducted on the natural convection characteristics of different nanofluids in various configurations of cavities due to the important applications of natural convection in environmental, petrochemical, medical, aviation and space technology, industrial and many more areas. The emergence of a magnetic field as a tool for the manipulation of convective flow and heat transfer behaviours of nanofluids in non-square enclosures has been extensively reviewed. The influence of several variables such as controlling parameters, heat distribution methods, thermal and concentration boundary conditions, magnetic field types, numerical methods, correlation types, nanofluid types, heaters types, numbers and length, and slip conditions, etc., on the magnetohydrodynamic (MHD) natural convection flow and heat transfer behaviours of nanofluid in non-square cavities has been given great attention and brought to the spotlight for discussion. The concepts of bioconvection, micro-polar nanofluid, bio-nanofluid (green nanofluid), ionic nanofluid, and hybrid nanofluid have also been discussed for the first time in relation to natural convection. Special cases of MHD natural convection in non-square cavities involving hybrid nanofluids and micro-polar nanofluids are also presented herein. The application of several numerical methods (which is the major approach studied so far) to investigate the hydromagnetic behaviours of nanofluids in non-square cavities is the focus of this work.
\end{abstract}

\subsection{Introduction}

The advent of nanofluids as coined by Choi [1], which is formulated through the dispersion of nano-sized materials (metals, non-metals, polymers, etc.) into based fluids (traditional and non-traditional fluids) has led to extensive research in the field of heat transfer. The huge demand for an effective and efficient thermal management due to the high quantum of heat required to be dissipated quickly from local points within various state-of-the-art devices, machinery, and systems has been a tall call long before now. This can be attributed to the low thermal conductivity of conventional working fluids and reaching of their threshold limits for the existing techniques of heat dissipation such as miniaturisation, surface extension (fins and micro-channels) and modification [2,3]. It has been proposed and researched that improving the thermal properties - especially thermal conductivity - of conventional working fluids can be a possible means of enhancing heat transfer and thus, better thermal management [4-11].

Nanofluids have been widely accepted as special fluids with inherent properties for improved thermal management compared to conventional fluids. The high surface-to-volume ratio of nanoparticles contained in nanofluids is responsible for the improved thermo-physical properties compared to the base fluids [11]. Pioneering studies on the convective heat transfer and flow engaged the dispersion of micro-sized and nano-sized particles in conventional fluids and they reported that nanofluids yielded improved convective flow and heat transfer without serious drawbacks for nanofluid in comparison to micro-particles fluids [12,13]. Also, the 
enhancement in the convective heat transfer and flow properties of nanofluids have been linked to the enhancement of the thermal conductivity.

Natural convection is an important means of flow and heat transfer that is induced by density variation (buoyancy) subject to a temperature gradient. Heat transfer and flow performance of nanofluids in cavities under natural convection are of great importance in various areas of application, especially, when the induced thermal flow is preferred at lesser power consumption, high system reliability, and insignificant operating noise [14]. Natural convection heat transfer and flow in cavities have several environmental and engineering applications such as molten metal purification, nuclear and chemical reactor coolers, food storage, heat exchangers, electronic systems, cooling, space technologies, insulation of building and thermal systems, petroleum and petrochemical industries, etc.

Several studies have been conducted on the natural convection of diverse nanofluids contained inside several shapes of enclosures and exposed to several thermal and boundary conditions [15-25]. The pioneering study on the natural convection of nanofluids in cavities was first reported by Khanafer and Co-workers [26] in 2003 , in which a numerical method was engaged to examine the natural convection of $\mathrm{Cu}$-water nanofluid in a square cavity. Thereafter, numerous studies have engaged several shapes of cavities, nanofluids, thermal and concentration boundary conditions, numerical techniques, controlling parameters, etc., to investigate the natural convection characteristics in the respective cavities. For studies in this regard, various configurations of cavity have been considered, namely; square [16,17,20,27], rectangular [28], C-shaped [21], U-shaped [29], L-shaped [30,31], triangular [32,33], open [34], half-moon shaped [23], cylindrical (ellipsoidal and circular) [35,36], semi-annulus [37], trapezoidal [25], concentric annulus [38], rhombic [39], hemispherical [40], parallelogrammic [41], T-shaped [42], $\Gamma$ [43], calabash-shaped [44], torus [45], semi- and quarter-circular [46,47], partitioned [48], complicated [49] and odd-shaped [50]. The most studied of the enclosures are the square-shaped while the most investigated thermal boundary condition is the two-dimensional isothermal differential heating of the vertical walls with adiabatic horizontal walls [14,27].

Furthermore, the insertion of obstacles of various shapes and the use of porous media in the cavities containing nanofluids have been explored as possible control measures to improve convection flow and heat transfer [31,33,52-54]. They revealed that heat transfer was enhanced using these controlling parameters. A critical observation of the studies showed that numerical methods were mostly employed with very few works using experimental and theoretically methods [55].

To enhance the thermophysical properties of nanofluids and consequently improving the natural convective heat transport and flow, different types of nanofluids have been utilised to investigate the natural convection characteristics in various cavities under several thermal boundary conditions for some controlling parameters. The thermo-convection behaviours of hybrid, ionic, bio-based, and micropolar nanofluids have been numerically investigated in cavities by some researchers [52,56-63]. Interestingly, the concept of bioconvection as first reported by Kuznetsov [64] has also been extended to studies (numerical) on natural convection, and in this case, both nanofluids and micro-organisms were employed in cavities $[65,66]$. A very close observation of published works in the public domain on the natural convection of nanofluids revealed research evolution following the trend of thermo-convection to thermomagnetic convection and not in too distant future, thermoelectric convection and thermomagnetic bioconvection. The present works of Sheikholeslami and Chamkha [67], Sheikholeslami and Bhatti [68], Khan et al. [69], and Khan et al. [70] bear claims to the latter.

In view of the emerging research direction on the natural convection of nanofluids in cavities, the benefit of manipulating convective heat transfer and flow using an external magnetic field is attracting unprecedented attention. The magnetic field stimulation of nanoparticles to augment the thermo-physical properties and the consequent improvement of convective flow and thermal transport characteristics in an enclosure is currently at the forefront of research in this field of study. Publications on the review of hydrothermal behaviours of nanofluids in cavities are few while a very limited number are carried on the magnetohydrodynamics (MHD) natural convection of nanofluids in various enclosures. This paper centred on the review of various studies on the influence of different types, directions, and configurations of magnetic fields on the natural convection 
of nanofluids contained in non-square cavities. The results of heat transfer and flow characteristics of hybrid nanofluids in non-square enclosures exposed to magnetic fields are also reviewed. To the best knowledge of the authors, this is the first review paper discussing thermomagnetic convection as related to hybrid nanofluids.

\subsection{MHD natural convection}

Great importance is attached to the natural convection transfer of heat in different configurations of cavities as space limitation is a challenge in the installation of devices, electronic components and machinery [71]. The present paradigm shift in technological advancement has led to the design of magnetic components and devices such as electronic devices cooling systems, magnetic storage media, and sensors that have high thermal performance and with non-square configurations [72]. Though MHD was first utilised in solving geophysical and astrophysical difficulties, it has evolved and attracting so much attention in several areas of application which include medical, agricultural engineering, petroleum engineering, space technology, nuclear reactors coolers, electronic components' cooling, geophysics, manufacturing (eg. MHD flow meter and pump), plasma physics, etc. [73,74]. The numerical approaches involved in the thermomagnetic convection studies of nanofluids inside cavities are discussed herein with attention focused on the modeling methods, heating methods, boundary conditions, containment of obstacles, magnetic field type, intensity, and orientation, and nature of enclosures (shape, porosity, inclination, etc.).

Many numerical works have been performed on the MHD natural convection of nanofluids inside non-square cavities. An overview of these studies showed the use of different thermal and concentration boundary conditions, partitioning, various temperature distribution methods, cavity inclination, different types of heaters, magnetic field types, orientation, and inclination, and various geometries of obstacles in the cavities, different nanofluid types, permeable media, different visualization methods, flow conditions, and nanofluid flow nature for investigating hydrothermal behaviours in non-square enclosures. The influence of various controlling parameters on the MHD convection performance of nanofluids in several non-square cavities has been reviewed. The numbers of publications (from 2003 to 2019) on the natural convection of nanofluids in cavities, non-square cavities, and for numerical methods and, experimental and theoretical methods in non-square cavities are illustrated in Figure 1. The statistics (2011 to date) for the publications on MHD convection of nanofluids in cavities, non-square cavities and for both numerical and, experimental and theoretical methods in non-square cavities are depicted in Figure 2. These data are sourced from the Scopus ${ }^{\circledR}$ database on the $24^{\text {th }}$ of December 2019. Table 1 shows a summary of the previous works conducted numerically on the hydromagnetic behaviours of nanofluids in non-square cavities in terms of the numerical technique and approach, nanofluid type and size, type and orientation of the magnetic field, controlling parameters, visualisation methods, remark, flow condition and nature, cavity description and diagram. In addition, Table 2 presents the special cases of MHD convection of hybrid nanofluids in non-square enclosures while Table 3 provides the correlations proposed for the prediction of $N u_{a v e}$ and $S_{g e n}$ in non-square enclosures under magnetic field stimulation. The classical/theoretical models and experimental-derived correlations used for the prediction of the thermophysical properties of nanofluids are given in Table 4.

\subsection{MHD natural convection in different enclosures (numerical)}

\subsection{Rectangular cavities}

Wang et al. [75] applied the LBM scheme to investigate the natural convection of a non-Newtonian power-law nanofluid (Cu-water) filled into rectangular cavities with different $A R s$ and subjected to a uniform magnetic field. The upper and lower sides of the cavity were thermally insulated while the vertical sides (right-cold and left-hot) were differentially heated. The uniform magnetic field was imposed axially on the right side of the cavity. Consideration was given to the effects of $A R, n, \varphi, H a$ and $R a$ on the MHD convection. They noticed that the exposure of the cavity to a magnetic field caused repression of nanofluid flow and heat transfer rate attenuated as $n$ and $H a$ increased. Also, an increase in $\varphi$ and $R a$ was observed to augment $N u$ . Maximum heat transfer enhancement was found at an optimum $A R$ value.

Sheikholeslami and Ganji [76] performed a numerical study (CVFEM) of the effects of $A, \varphi, H a$ and $R a$ 
on the MHD convection of a water-based $\mathrm{Fe}_{3} \mathrm{O}_{4}$ nanofluid in a rectangular cavity having a sinusoidal vertical side. The top and bottom sides of the cavity were insulated. The vertical wall (right) was assumed hot while the left vertical sinusoidal wall was cold. An external magnetic field was imposed vertically upward on the bottom of the cavity. They observed that the $N u_{\text {ave }}$ enhanced with $A, \varphi$, and $R a$ (at low values of $R a$ but the reverse if high) but it degraded with $\mathrm{Ha}$. As the distance between the hot and cold walls reduced (low buoyancy force) temperature gradient was augmented. In addition, the temperature gradient was noticed to increase with $A$, and $H a$ but it diminished with $R a$ and $\varphi$.

An earlier study using the same cavity as Sheikholeslami and Ganji [76] but with different thermal boundary conditions, nanofluid and magnetic field point of application was conducted by Sheikholeslami et al. [77]. They employed the CVFEM scheme to investigate the MHD natural convection of a CuO-water nanofluid contained in a rectangular cavity with a constant heat flux sinusoidal wall. Both the top and bottom walls of the cavity were kept adiabatic, the left vertical sinusoidal wall was under constant heat flux and the right vertical wall was assumed cold. KKL correlation was used for thermal conductivity and viscosity estimation in the model to account for the Brownian motion effect in the nanofluid. Their results were found to be similar to those reported by Sheikholeslami and Ganji [76] with $N u_{a v e}$ enhanced as $\varphi, R a$, and $A$ increased but it attenuated as $H a$ surged. A correlation was formulated to estimate the $N u_{\text {ave }}$ based on the governing parameters.

Shahriari et al. [78] examined the influence of $R a, H a, \vartheta$, and $\varphi$ on the hydrothermal behaviour and entropy generation of a water-based $\mathrm{CuO}$ nanofluid in a wavy-walled rectangular enclosure (inclined) using LBM technique. The horizontal sides of the cavity were assumed adiabatic, while the left (wavy) and right vertical sides were sinusoidally heated and sustained at a cold temperature, respectively. A uniform magnetic field was imposed perpendicular to the left side of the enclosure. Their findings showed the improvement of $S_{g e n}$ and heat transfer as $R a$ rose and they reduced as $H a$ augmented. At $R a=10^{5}$, the $N u$ and $S_{g e n}$ were noticeable with an increase in $\varphi$. For $R a=10^{5}$, the $N u_{\text {ave }}$ diminished from $\vartheta=0$ to $\pi / 3$ while $S_{\text {tgen }}$ increased from $\vartheta=0$ to $\pi / 4$.

Recently, Rahmati et al. [79] analysed the hydromagnetic heat transfer of water-based CuO nanofluid inside tall rectangular cavities (horizontal, vertical, and inclined) using FVM. The top and right vertical walls of the cavity were kept hot while the left vertical and bottom walls were maintained at low temperatures. The cavity was exposed to a magnetic field (horizontal). The influence of $H a, \varphi$, and cavity orientation was considered. They concluded that at $\varphi=1 \%$ the $N u$ ave was enhanced by $10.5 \%-17.5 \%$ for the three cavities relative to the base fluid, when $H a$ was increased from $0-600$. Increasing $\varphi$ from $1 \%-4 \%$ was observed to enhance $N u$ ave by $1.35 \%-4.90 \%$ on increasing $H a$ from $0-600$. Also, the inclined cavity was noticed to enhance heat transfer better than the horizontal and vertical cavities. It can be deduced that using $\varphi=1 \%$ and the inclined cavity as an individual parameter yielded the highest heat transfer.

A rectangular cavity enclosing a porous medium saturated with a water-based $\mathrm{Cu}$ nanofluid and under the influence of an inclined uniform magnetic field was investigated for the natural convection behaviour using finite difference method (FDM) [80]. Both the horizontal and vertical sides of the cavity were kept at low temperatures and adiabatic, respectively. The nanofluid was assumed to generate heat at a constant volumetric rate. The impact of the external magnetic field, internal generation of heat and pertinent parameters $\left(H a, \gamma\right.$, and $\varphi$ at $\left.R a=10^{3}\right)$ on the natural convection flow characteristics of the enclosure was monitored. They observed that $N u_{\text {ave }}$ was an increasing function of $\gamma$ while it was a decreasing function of $\varphi$ and $H a$ - The maximum stream function value diminished when Hawas increased while the maximum temperature appreciated with $\mathrm{Ha}$.

It is generally observed that in a rectangular cavity containing nanofluids heat transfer was enhanced with $A, R a$, ?, and $\gamma$ but it attenuated with $H a$. However, heat transfer was noticed to deteriorate with an increase in ? and the highest heat transfer occurred at optimum values of $A R$ and $\vartheta[80]$. This is probably because of the porous media contained in the cavity.

\subsection{Circular cavities}


The applicability of circular cavities to the MHD natural convection of nanofluids has been researched. Sheikholeslami et al. [81] applied the CVFEM technique to study the effect of $M n, \varphi, H a$ and $R a$ on the natural convection performance in a half-circular enclosure containing a water-based $\mathrm{Fe}_{3} \mathrm{O}_{4}$ nanofluid in the presence of a magnetic field source. The outer and inner surfaces of the enclosure were maintained at low and high temperatures, respectively, whereas the vertical and horizontal surfaces were insulated. The magnetic field source was located on the outer circular surface of the cavity. The model formulation accounted for both Kelvin and Lorentz forces. They found that the $N u$ was enhanced as $M n, \varphi$, and $R a$ increased but depreciated as $\mathrm{Ha}$ increased. It was also noticed that at high $\mathrm{Ra}$, increasing Kelvin forces enhanced heat transfer whereas increasing Lorentz forces reduced it. The increase in Lorentz forces caused attenuation of temperature gradient which was enhanced as Kelvin forces increased.

Al-Zamily [82] utilised the FEM technique to analyse the influence of $\varphi, H a$ and $R a$ on the natural convection of $\mathrm{Cu}$-water inside a semi-circular cavity under an externally applied constant magnetic field. A part of the bottom wall of the cavity was maintained at a constant heat flux while the other parts were kept thermally insulated. A part of the cavity (arc center) was sustained at a cold temperature while the rest was maintained adiabatic. The orientation of the uniform magnetic field was parallel to gravity. This work employed heat functions along isotherms and streamlines for heat flow visualization. The results indicated the enhancement of heat transfer as $\varphi$ and $R a$ increased, nonetheless, it declined as $H a$ increased. Also, it was noticed that the presence of the magnetic field enhanced heat transfer as $R a$ increased but the reverse is the case as $\varphi$ increases. This result was found to be in good agreement with previous studies discussed for rectangular cavities and half-circular cavity by Sheikholeslami et al. [81].

CVFEM was utilised as a numerical technique to examine the impact of $m, \varphi, R d, D a, H a$, and $R a$ on the natural convection behaviour in a permeable semi-circular cavity (having a wavy outer surface) containing a $\mathrm{Fe}_{3} \mathrm{O}_{4}$-water nanofluid and subjected to external magnetic source stimulation [83]. The outer and inner surfaces of the enclosure were at low and high (constant heat flux) temperatures, respectively, while the bottom surfaces were thermally insulated. The problem formation considered four shape factors for the nanoparticles and their influence on the thermal conductivity of the nanofluids. In addition, temperature, magnetic field strength, and $\varphi$ dependent viscosity correlation and shape factor-related thermal conductivity correlation were employed in the study. The nanoparticles with the platelet shape $(m=5.7)$ were found to yield the highest $N u$. The augmentation of $N u$ as $R a$ and $D a$ increased and its attenuation as $H a$ surged was observed.

Using a half-moon shaped cavity (with semi-circular heaters) enclosing Co-kerosene and $\mathrm{Fe}_{3} \mathrm{O}_{4}$-water nanofluids, Mojumder et al. [73] numerically analysed the entropy generation and hydromagnetic behaviour with the aid of FEM technique. For the enclosure, the outer semi-circular wall was at a low temperature, the horizontal bottom walls were thermally insulated while the bottom semi-circle walls were heated using the semi-circular heaters. The role of $\mathrm{Ra}, \gamma, \mathrm{Ha}, \varphi$ and distance between the heaters on the hydromagnetic characteristics and entropy generation of the nanofluids were carried out. They found that the heat transfer rate was considerably enhanced by increasing heater distance but deteriorated with the magnetic field influence. At $\lambda=0.4$, the $N u$ and heat transfer rate was improved, and $S_{\text {gen }}$ was optimised for all $\gamma, R a$, and $H a$ values. Furthermore, heat transfer augmentation and $S_{g e n}$ optimisation were observed when $R a$ was high, $H a$ was low, $\gamma$ was moderate $\left(45^{\circ}\right)$, all at an optimum $\varphi$.

The hydromagnetic behaviour of nanofluids in circular enclosures was generally observed to be associated with heat transfer augmentation as $R a, \varphi$, and $D a$ increased and deterioration with $H a$. However, the augmentation of heat transfer was reported at optimal values for $H a, \gamma, R a$, and $\varphi$ as reported by Mojumder et al. [73]. The presence of heaters may be responsible for this observation. More studies are required for the MHD convection of nanofluids in circular cavities, especially, with magnetic field inclination and porous cavities since limited works were conducted in this regard.

\subsection{Annulus cavities}

Various annulus geometries with the imposition of different thermal boundary conditions were studied for 
the MHD convection characteristics of diverse nanofluids contained in them. Sheikholeslami and Ganji [84] applied CVFEM to examine the natural convection heat and flow of a water-based $\mathrm{Fe}_{3} \mathrm{O}_{4}$ nanofluid in a semi-annulus cavity under the existence of the magnetic field. For the cavity, the horizontal walls were insulated, the outer circular surface was at a cold temperature while the inner sinusoidal surface was maintained hot. The magnetic field source was centrally located beneath the inner sinusoidal wall of the cavity. The influence of $M n, \varphi, R a$ and $H a$ were examined. Their findings indicated that increasing $\varphi$ and $R a$ caused the enhancement of $N u$ which declined when $H a$ was increased. They observed that at low $R a$, heat transfer was augmented as Haincreased and $M n$ reduced but the reverse was the case at high $R a$ values. Subject to $R a$, the influence of $M n$ on the $N u$ was noticed to be different.

The impact of $\mathrm{Ra}, \varphi$, and $\mathrm{Ha}$ on the MHD natural convection of water-based $\mathrm{Fe}_{3} \mathrm{O}_{4}$ inside a semi-annulus cavity with a constant heat flux heating was investigated by applying the FEM scheme [85]. The outer surface of the enclosure was thermally insulated, the horizontal bottom surfaces were at cold temperatures while the inner surface was under a constant heat flux heating. A non-uniform and radially applied magnetic field was imposed beneath the inner surface of the cavity. They concluded that increasing $R a$ and $\varphi$ were responsible for the augmentation of heat transfer which declined with $H a$, and the same relationship was observed for $N u_{\text {ave }}$.

The effect of an external magnetic field on the thermo-convection heat transfer of $\mathrm{Fe}_{3} \mathrm{O}_{4}$-water in an annulustype enclosure was studied using CVFEM [86]. The cavity involved a square-shaped cylinder (with walls at cold temperatures) enclosing a centrally placed circular cylinder with the walls (inner) at constant heat fluxes. The external magnetic field was applied on top of the enclosure. Parameters considered for the nanofluid MHD influence were $R a, \varphi$, and $H a$. The result showed that the depth of the thermal boundary layer and the velocity of the nanofluid was enhanced and reduced, respectively, with the application of Lorentz forces. Also, the heat transfer enhancement of the nanofluid was noticed when the Lorentz force increased. $N u$ was found to increase with thermo-convection while it reduced with thermomagnetic convection. The addition of the nanoparticles was noticed to favour the increase in $N u$ at high $H a$ and low $R a$ values. Furthermore, they developed a correlation to estimate $N u$ ave using $R a, H a$, and $\varphi$ as variables.

Sheikholeslami and Co-workers [87] numerically analysed the MHD natural convection in a seemingly similar cavity as performed by Sheikholeslami and Rokni [86] using the LBM scheme except in the heating method, type, and point of application of the magnetic field, nanofluid type, and governing parameters. An agreement was observed between the obtained result for both studies in terms of the relationship of $H a$, $\varphi$, and $R a$ to $N u$. This work also demonstrated maximum heat transfer enhancement at $H a=20$ for $R a=10^{4}$ and at $H a>20$ for $R a=10^{5}$.

Selimefendigil and Öztop [74] studied the natural convection behaviour in a partitioned annulus (horizontal) cavity containing $\mathrm{CuO}$-water nanofluid in the presence of an inclined magnetic field using FEM. The partition in the enclosure was filled with a conductive ring (full) having varied the thermal conductivity and thickness. The walls of the outer and inner cylinders were maintained at the constant cold and hot temperatures, respectively. How $K_{p}, \varphi, \gamma, H a$ and $R a$ affect thermo-convection behaviour of the nanofluid in the cavity for different thicknesses of partition was examined. The result showed that an increase in $R a, \gamma$ (below $45^{\circ}$ ) and $K_{p}$ caused an enhancement of both the $N u_{a v e}$ and $N u_{l o c}$ (across the inner surface of the cylinder), which reduced with an increase in $H a$. It was noticed that as $K_{p}$ increased the mean heat transfer increased. In addition, $\varphi$ was found to be directly proportional to $N u_{\text {ave }}$.

A horizontal annulus cavity with an inner triangular cylinder containing an $\mathrm{Al}_{2} \mathrm{O}_{3}$-water nanofluid under an external magnetic field was analysed using LBM [88]. The effect of Brownian motion on the nanoparticles and that of $H a, \varphi$, and $R a$ on the natural convection heat transfer was considered in the analysis. The inner triangular cylinder and the outer circular cylinder were maintained at high and cold temperatures, respectively. The use of KKL correlations for modeling of thermal conductivity and viscosity of the nanofluid was reported. They indicated that the enhancement of $N u$ increased with $R a$ and decreased with $H a$. A correlation relating $\mathrm{Nu}$ to both $\mathrm{Ra}$ and $\mathrm{Ha}$ has been developed in this study. Also, the importance of coupling LBM and double population for the natural convection simulation especially in the curved boundary region 
has been stressed.

Sheikholeslami and Co-workers [89] examined the effect of $H a, \varphi, e, R a$, and $a_{e c}$ on the MHD natural convection of a water-based $\mathrm{CuO}$ nanofluid contained in an annulus cavity with a hot elliptic cylinder (inner). The cavity was under the presence of a magnetic field imposed axially from the left side. The outer cylinder was assumed to be at a cold temperature while the inner elliptic cylinder was sustained hot. Both the KKL correlation and the Darcy model were incorporated into the numeral analysis. They demonstrated that an increase in $a_{e c}$ and $R a$ enhanced heat transfer, but $N u$ depreciated with $H a$ and $e$. At high $H a$, the influence of $\mathrm{CuO}$ nanoparticles addition increased as Lorentz forces rose. In addition, they proposed a correlation for the estimation of $N u_{\text {ave }}$.

With the exposure of a water-based $\mathrm{Fe}_{3} \mathrm{O}_{4}$ nanofluid contained in an annulus cavity (having a hot inner elliptic cylinder) to both thermal radiation and magnetic field effects, the natural convection flow and heat transfer was numerically performed using CVFEM approach [90]. For the enclosure, the outer elliptic cylinder was at a cold temperature while the inclined inner elliptic cylinder was maintained at a constant heat flux. The magnetic field was imposed along the x-axis from the left side of the enclosure. The examined parameters were $\varphi$ of $\mathrm{Fe}_{3} \mathrm{O}_{4}$ nanofluid, $R d, H a, \zeta$ and $R a$. In the problem formulation, the viscosity was considered as a function of both temperature and magnetic field strength when a correlation was used. They found $N u$ enhancement to be a function of $R a$ and $R d$, which diminished with $H a$. Increasing $\zeta$ was noticed to augment the rate of heat transfer. Also, the temperature of the inner wall appreciated with $R d$ and $H a$ but degraded with $\zeta$ and $R a$. A correlation was derived to estimate $N u_{a v e}$. Dogonchi et al. [91] investigated the hydromagnetic heat transfer characteristics in an annulus (a rhombic cylinder inside a triangular cylinder) cavity filled with water-based $\mathrm{Fe}_{3} \mathrm{O}_{4}$ nanofluid. The inner rhombus-shaped cylinder provided the heating in the cavity while the walls of the outer triangular cylinder were kept cold. The magnetic field was imposed at an angle on the cavity. An examination of the impact of $R d, A R, H a, \varphi, m$, and $R a$ on the heat transfer carried out. They found that increment in $R d, \varphi$, and $R a$ resulted in the enhancement of $N u_{a v e}$ whereas increasing $A R$ and $H a$ caused attenuation of $N u_{\text {ave }}$. Again, the platelet with a shape factor of 5.7 yielded the highest enhancement of heat transfer.

The impact of $A, H a, \varphi$, and $R a$ on the MHD convection of a water-based $\mathrm{Fe}_{3} \mathrm{O}_{4}$ nanofluid contained in a curvilinear cavity was performed by Sheikholeslami and Oztop [92] in which the CVFEM scheme was applied. The outer (sinusoidal) and inner surfaces of the enclosure were assumed to be at cold and hot temperatures, respectively, while an external magnetic field was imposed below the inner surface. Their result revealed the

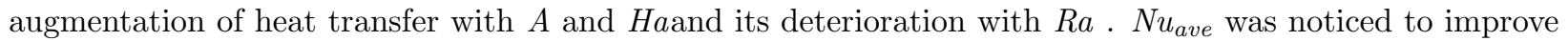
with $\varphi$ increase. They also developed a formula for estimating $N u_{a v e}$. Dogonchi and Hashim [93] examined free convection in an annulus cavity (rhombus inside the circular cylinder) containing $\mathrm{Fe}_{3} \mathrm{O}_{4}$-water nanofluid and under a magnetic excitation. The outer wavy cylinder and inner rhombus of the cavity were subjected to constant low and high temperatures, respectively. The magnetic field was applied at an angle to the cavity. Parameters such as $R d, A R, H a, \varphi, m$, and $R a$ were considered. They observed that increasing $R d, R a$, and $m$ augmented $N u_{a v e}$ while it was detracted as $A R$ and $H a$ increased. Platelet-shaped (m $=$ 5.7) nanoparticles were noticed to enhance heat transfer better than other shapes.

Recently, Li et al. [94] analysed the MHD heat transfer convection in a sinusoidal annulus cavity filled with $\mathrm{Fe}_{3} \mathrm{O}_{4}$-water nanofluid using the CVFEM technique. Similar to the work of Sheikholeslami and Oztop [92], the inner cylinder wall of the cavity was subjected to a constant heat flux while the outer cylinder wall was kept cold. The magnetic field was imposed on the left vertical wall of the cavity. The influence of $H a$, $R a$ $, \varphi, N$, and $R d$ was considered in the study. Result demonstrated that heat transfer was enhanced as $R a$ and $R d$ increased and it attenuated with an increase in $H a$, and $N$. In addition, Hajmohammadi et al. [95] employed single- and two-phase approach to investigate the natural convection heat and flow behaviour of water-based $\mathrm{Cu}$ in an annulus cavity with outer (fixed) and inner (rotary) cylinders that were exposed to a uniform magnetic field. The surface of the cylinders was maintained at a low temperature while a constant heat flux was applied on the outer/inner cylinder's surface. Magnetic excitation was imposed on the axis of cylinders. The influence of $\mathrm{N}_{\mathrm{bt}}, H a$, and $\varphi$ was examined. They reported that $H a$ has the most effect on 
heat transfer and flow than $\mathrm{N}_{\mathrm{bt}}$ and $\varphi$. Increasing $H a$ was observed to reduce heat transfer and the outer ring shear stress but at $\mathrm{Ha}>22$, heat transfer and inner ring shear stress were enhanced. At $\mathrm{N}_{\mathrm{bt}}=25, \varphi$ $=0.05$, and $H a=20$, heat transfer and outer ring shear stress were noticed to reduce by $11 \%$ and $86 \%$, respectively, compared to the case of $H a=0$.

An inclined semi-annulus cavity under an inclined uniform magnetic field containing $\mathrm{Cu}$-water was employed to numerically analyse the natural convection flow and heat transfer using (DRBEM) and considering $\varphi, \vartheta$ and $\gamma, R a$ and $H a$ [96]. The cavity outer and inner walls were maintained at a cold temperature and under a constant heat flux, respectively, while the remaining walls were adiabatic. Results indicated a reduction of heat transfer and $N u_{a v e}$ as $H a$ increased but intensified with $R a$. Nu decreased with $H a$ as $\vartheta$ reduced. They concluded that the augmentation of the convection heat transfer and flow in the cavity can be controlled through $\vartheta$ and $\gamma$. The effectiveness and reliability of the DRBEM scheme in this study were stressed, which agreed with the view stated in previous work [97]. Similarly, a previous study by Sheikholeslami et al. [98] using the same cavity, boundary conditions, nanofluids, governing parameters but a different numerical technique (CVFEM), showed that $\vartheta$ and $H a$ at various $R a$ values can be employed to control heat transfer and flow behaviours of nanofluids in semi-annulus cavities. Also, the weakening of the velocity flow field under magnetic field presence caused the declination of $N u$ and heat transfer.

Sheikholeslami et al. [99] used a permeable semi-annulus cavity containing $\mathrm{Fe}_{3} \mathrm{O}_{4}$-water nanofluid and exposed to both thermal radiation and magnetic field source to numerically (CVFEM) study the thermoconvection heat transfer and flow. The inclined sides of the cavity were kept adiabatic, while the outer and inner curved sides were maintained at a low temperature and a constant heat flux, respectively. The magnetic field was inclined at $45^{\circ}$ and imposed on the cavity. The influence of $R d, R a, \varphi$, and $M n$ due to ferrohydrodynamic, and $H a$ subject to MHD was considered. They reported the positive effect of $\varphi, M n$, and $R a$ on $\mathrm{Nu}$, which depreciated with $R d$ and $H a$.

Similarly, Sheikholeslami et al. [100] carried out a numerical analysis (CVFEM) of MHD natural convection on a water-based $\mathrm{Fe}_{3} \mathrm{O}_{4}$ nanofluid filled into a porous double sinusoidal-walled semi-annulus cavity under thermal radiation. The horizontal walls were thermally insulated while the outer and inner sinusoidal walls were kept at a low temperature and a constant heat flux, respectively. The magnetic field source was centrally positioned below the inner wall. Viscosity was estimated from a temperature, magnetic field strength and $\varphi$ dependent correlation and thermal conductivity were also calculated using a correlation having a shape factor and $\varphi$ as functions. The impact of pertinent parameters ( $R d, H a, \varphi, R a, D a$, and $m)$ on the flow and heat transfer were monitored. They demonstrated that the temperature gradient enhanced with $D a$ and $R a$ and attenuated with $H a$. Increasing $H a$ was observed to depreciate the heat transfer rate and nanofluid flow. Maximum $N u$ was attained using platelet, cylinder, brick and then spherical-shaped $\mathrm{Fe}_{3} \mathrm{O}_{4}$ nanoparticles (decreasing order). Using the pertinent parameters as functions, a correlation was proposed for predicting $N u_{\text {ave }}$.

CVFEM was applied by Sheikholeslami and Rokni [101] to investigate the effects $\vartheta, \varphi, R a, H a$ and $D a$ on the MHD natural convection of a water-based $\mathrm{Fe}_{3} \mathrm{O}_{4}$ nanofluid inside a permeable annulus cavity with a hot inner inclined square obstacle. The outer cylinder wall was at a cold temperature while the square obstacle walls were providing heat at constant heat fluxes. The enclosure was under external magnetic field influence imposed along the x-axis. A non-Darcy model and a viscosity correlation (as a function of temperature and strength of magnetic field) were utilised in this study. They proved that $N u_{\text {ave }}$ was enhanced with $D a, \vartheta$,and $R a$, and it diminished with $\mathrm{Ha}$. Heat transfer was augmented as $\vartheta$ rises but depreciated as $H a$ increases.

A porous semi-annulus cavity encompassing a water-based $\mathrm{CuO}$ nanofluid in the presence of a magnetic field was investigated using CVFEM [102]. The outer elliptical cylinder was kept at a low temperature while the inner circular cylinder was maintained at a hot temperature. A constant magnitude magnetic field was axially imposed on the cavity. The impact of $\varphi$, Brownian motion, $\vartheta, R a$ and $H a$ on the thermo-convection flow and heat transfer were considered. KKL correlations for viscosity and thermal conductivity were incorporated into the model formulation to account for the Brownian motion effect. Their results showed a weakening of temperature gradient as Haincreased, nonetheless, it intensified as $R a$ and $\vartheta$ increased. The enhancement of 
heat transfer was also observed with a magnetic field rise. The increase in $\varphi$ and $R a$ led to augmentation of $N u_{\text {ave }}$ but the reverse occurred when $H a$ and $\vartheta$ increased. $N u_{a v e}$ correlation as a function of $\vartheta, R a$ and $H a$ were developed for this study.

With the same nanofluid and a different configuration of the porous semi-annulus cavity to that reported by Sheikholeslami and Ganji [102], the MHD natural convection was numerically performed by Sheikholeslami and Shehzad [103] using CVFEM. The outer rectangular-shaped cylinder of the enclosure was at a low temperature while the inner circular cylinder supplied a constant heat flux. An external magnetic field was applied axially at the centre of the cavity. The KKL correlation was utilised along with a Darcy model for the numerical model formulation. The pertinent parameters of $H a, \varphi, R a$, and $r_{i n}$ were explored. Their findings indicated the enhancement of $N u_{a v e}$ with the rise of $R a, \varphi$ and $r_{i n}$, whereas it declined as Lorentz forces increased. Heat transfer was found to reduce as $\mathrm{Ra}$ appreciated. At high $\mathrm{Ha}$ values, the addition of nanoparticles was noticed to be significant. In addition, a correlation was established for the $N u_{\text {ave }}$ estimation based on the pertinent parameters considered.

Sheikholeslami and Seyednezhad numerically (CVFEM) investigated the natural convection behaviour in a complex enclosure (having a constant heat flux inner wall) containing a $\mathrm{Fe}_{3} \mathrm{O}_{4}$-water nanofluid, which was under the existence of a non-uniform magnetic field [104]. The horizontal surfaces of the cavity were insulated, the outer sinusoidal surface was kept adiabatic while the inner semi-elliptic surface was heated at a constant heat flux. The magnetic field source was located beneath the inner wall of the enclosure. Correlations outside the classical models were engaged to calculate the viscosity and thermal conductivity for this study. The influence of $D a, R d, R a, \varphi, m$, and $H a$ on the MHD convection were explored. Their results showed that an increase in $R d, D a$, and $R a$ led to $N u$ enhancement which declined with $H a$ and pincrement. In addition, increasing $H a, R a$ and $D a$ were noticed to enhance heat transfer rate and the platelet-shaped nanoparticles yielded the maximum heat transfer of all the shapes of $\mathrm{Fe}_{3} \mathrm{O}_{4}$ nanoparticles. A correlation was proposed to calculate the $N u_{a v e}$ as functions of the controlling parameters.

Sheikholeslami and Ganji [105] applied CVFEM to study the influence of $R a, H a, D a$ and $\varphi$ on the MHD convection of a water-based $\mathrm{Fe}_{3} \mathrm{O}_{4}$ nanofluid in a porous annulus cavity. The outer and inner (elliptic) cylinders were maintained at cold and hot temperatures, respectively, while the magnetic field was located beneath the inner cylinder. They found that heat transfer augmented with $R a, D a$, and $\varphi$ but it detracted with $\mathrm{Ha}$, which is consistent with the work of Sheikholeslami and Seyednezhad [104], though using a relatively different cavity and thermal boundary condition. A formula for estimating the average $N u_{\text {ave }}$ was also proposed.

The influence of a magnetic field presence on a porous annulus cavity (with a hot inner rectangular cylinder) containing a water-based $\mathrm{CuO}$ nanofluid was investigated [106]. Both the outer and inner surfaces of the cavity were sustained at a cold temperature and a constant heat flux, respectively. The magnetic field was imposed axially on the cavity. The CVFEM scheme was engaged in the work and, KKL and Darcy models were utilised to account for the Brownian motion effect in porous media. Effects of $\zeta, \varphi, R a$ and $H a$ on the natural convection flow were observed. Their findings revealed the intensification of $N u_{\text {ave }}$ with $\varphi$ and $R a$ and attenuation with $H a$ and $\zeta$. In addition, it was observed that heat transfer deteriorated with $R a$ and appreciated with $H a$ and $\zeta$. A correlation was derived to predict $N u_{a v e}$.

Sheikholeslami and Shehzad [107] used a $\mathrm{CuO}$ water-based nanofluid contained in a porous annulus cavity (with an inner elliptic cylinder) exposed to a magnetic field to study the natural convection heat transfer performance by applying CVFEM and using the two-phase approach. The outer and inner elliptic cylinders of the enclosure were assumed to be isothermally cold and hot, respectively, while the magnetic field was axially imposed on the left side of the cavity. The KKL model was utilised to estimate thermal conductivity and viscosity while the effect of $\mathrm{Ha}, \mathrm{Ra}, \xi$, and $N h s$ was inspected. They showed that the flow was augmented with $N h s$ and $\xi$, and it detracted with $H a$. Also, the deterioration of $N u_{a v e}$ was observed as $\xi$ , Nhs, and $H a$ augmented. They formulated a correlation to predict $N u_{\text {ave }}$. These results agreed with that reported by Sheikholeslami and Rokni [108], in which they examined the MHD convection in a relatively identical cavity with the same thermal boundary conditions, nanofluid ( $\mathrm{CuO}$ water-based) and controlling 
parameters as this work [107]. A correlation to predict $N u_{\text {ave }}$ was also developed.

Sheikholeslami and Shehzad [109] used CVFEM to examine the hydromagnetic behaviour of a water-based $\mathrm{Fe}_{3} \mathrm{O}_{4}$ nanofluid contained in a porous annulus cavity (with a hot inner elliptic cylinder). The top and vertical sides of the cavity were kept at cold temperatures, the lower walls were insulated while the walls of the inner elliptic cylinder provided heat at a constant heat flux. The non-uniform magnetic field was radially imposed beneath the inner elliptical cylinder wall. Both the impact of nanoparticles' shape factors and controlling parameters $(R d, H a, R a, \varphi$, and $D a)$ were considered. They showed that heat transfer enhancement was an increasing function of $D a$ and $R a$ and a decreasing function of $H a$. The highest $N u$ was attained with nanoparticles having a platelet shape.

Dogonchi et al. [110] analysed the MHD convection in a porous annulus cavity filled with CuO-water nanofluid exposed to an inclined magnetic field using the CVFEM scheme. The inner rectangular and outer circular cylinders were kept hot and cold, respectively, while the rest of the cavity was thermally insulated. The inclined magnetic field was applied on the left side of the cavity. The effect of $H a, R a, \varphi, D a, m$, and $\gamma$ on the heat transfer was examined. The result demonstrated the improvement of $N u$ ave as $R a, \varphi, D a$, and $m$ increased and as $H a$ and $\gamma$ reduced. At $H a=25$ and $R a=10^{5}$, heat transfer improved by $16 \%$ as $\varphi$ increased whereas heat transfer was detracted by $9 \%$ when $H a=0$. In addition, the $N u$ ave was attenuated by $15 \%\left(R a=10^{5}\right)$ when Haincreased from $0-25$. Change in the shape of the nanoparticles from a sphere $(m=3)$ to platelet $(m=5.7)$ was noticed to result in a $5 \% \mathrm{Nu}$ enhancement.

The engagement of different types of annulus cavities for the hydromagnetic performance of various nanofluids showed that heat transfer was majorly augmented with an increase in $R a, \varphi, D a, m, R d, A R, \vartheta, \zeta$, and $\gamma$, and it deteriorated as $H a$ increased. However, the reverse was reported for $H a$ [92], $R d$ [99], $A R$ [93], and $\gamma[110]$ in relation to heat transfer enhancement while maximum heat transfer was recorded at optimum values for $H a[95], \zeta$ [106], and $\gamma$ [74]. The research gap observed with the use of this cavity-type was in the employment of $\vartheta, A R$, and $\gamma$ to improve heat transfer.

\subsection{Triangular cavities}

Different types of triangular cavities were employed in analysing the MHD convection of nanofluids contained in them. Mahmoudi et al. [111] employed the FVM technique to analyse the MHD natural convection in a partly-heated (bottom wall) triangular cavity containing $\mathrm{CuO}$-water nanofluid. The vertical and diagonal walls of the cavity were insulated and maintained at a low temperature, respectively, while a constant heat flux was suppled at the bottom wall using two heat sources. An external magnetic field was vertically applied to the cavity. Six cases of partial heating of the lower wall of the enclosure in addition to the pertinent parameters of $\varphi, H a$ and $R a$ were considered. They reported the attenuation of the flow field, heat transfer, and $N u_{\text {ave }}$ as the magnetic field increased. At $R a=10^{6}$, the lowest $N u_{\text {ave }}$ was noticed for high $\mathrm{Ha}$ and the addition of nanoparticle was profound at $R a=10^{4}$. The use of a correlation for the thermal conductivity evaluation in the model other than the classic model was reported.

Rahman and Co-workers [112] performed the natural convection of a water-based $\mathrm{Al}_{2} \mathrm{O}_{3}$ nanofluid filled into an isosceles triangular in the presence of a uniform magnetic field using FEM. The bottom wall of the cavity was exposed to three thermal boundary conditions at a high temperature and concentration while the inclined vertical sides were sustained at cold temperatures. The cavity was exposed to an inclined uniform magnetic field. The influence of thermophoresis and Brownian motion was embedded in the numerical simulation and the pertinent parameters of $\gamma, R a$ and $H a$ were examined. They demonstrated that heat transfer improved when $R a$ increased and nanoparticle diameter reduced, whereas it deteriorated as $\gamma$ and $\mathrm{Ha}$ increased. Furthermore, the uniform heating of the wall was found to be the best mode of heating because it produced the thickest thermal boundary layer.

FEM with a two-component non-homogeneous model was employed to study the MHD natural convection heat transfer of $\mathrm{Fe}_{3} \mathrm{O}_{4}$-water and Co-kerosene nanofluids enclosed in an equilateral triangular cavity [113]. For this cavity, the inclined faces were kept isothermal and the bottom face was heated at varying non-uniform temperatures. An inclined magnetic field was imposed on the enclosure. The author fused thermophoresis 
and Brownian motion of the $\mathrm{Fe}_{3} \mathrm{O}_{4}$ nanoparticles into the model and examined the influence of $\gamma, \mathrm{Ha}$, and Ra on the rate of heat transfer of the ferrofluids contained in the enclosure. They reported considerable heat transfer enhancement as $\gamma$ increased and the contrast when $H a$ was increased. Co-kerosene nanofluids were noticed to have higher rates of heat transfer compared to the $\mathrm{Fe}_{3} \mathrm{O}_{4}$-water nanofluids, and this was because the applied magnetic field has a stronger effect on the former than the latter in the augmentation of heat transfer. It was also observed that the isoconcentrations profile of this cavity was analogous to those of the streamlines under the influence of $\gamma$. This signified the importance of this cavity for engineering application in attaining uniform nanoparticles concentration coupled with the fully developed flow.

Recently, Dogonchi et al. [114] examined the natural convection heat and flow transfer in an irregular triangular cavity containing $\mathrm{Cu}$-water nanofluid exposed to an external magnetic stimulus. The inclined walls of the cavity were maintained cold while the irregular base wall was heated, and the horizontal base walls were kept adiabatic. The magnetic field stimulus was applied horizontally on the left side of the cavity. The impact of $m, \varphi, H a$, and $R a$ was considered. They demonstrated that heat transfer and flow rate were augmented as $m, \varphi$, and $R a$ increased which attenuated with $H a$. However, increasing $R a$ and Hacaused the enhancement of $N u$. Of the shape factors studied, the platelet influenced heat transfer the most.

Dogonchi et al. [115] considered the effect of $H a, R a, A R$, and $\varphi$ on the thermo-convection of Cu-water nanofluid in a triangular cavity (with semi-circular base) under a uniform magnetic field by engaging the CVFEM technique. The cavity's inclined walls were kept at a low temperature while the horizontal walls were insulated, and the semicircle-shaped base was maintained at a high temperature. The magnetic field was imposed horizontally on the left side of the cavity. They proved that the $N u$ avewas augmented as $R a$ and $\varphi$ increased and as $H a$ and $A R$ decreased. At $R a$ [?] $10^{4}$, reducing the radius of the semi-circular base of the cavity was observed to attenuate $\mathrm{Nu}$ ave. Ahmed et al. [116] studied the MHD convection heat transfer in a porous triangular cavity filled with water-based $\mathrm{Cu}$ nanofluid using the FVM technique. The inclined wall was maintained cold while the bottom wall on which the fin was mounted was insulated. When a heat source was placed on the vertical wall the fin was kept cold while when a heat sink was located on the vertical wall the fin was maintained hot. The remaining part of the vertical wall (outside the heat source/sink) was kept adiabatic. An inclined magnetic field was imposed on the cavity. The two forms of heating were examined along with the influence of $H a, H \mathrm{f}, W, B, D, D_{f}$, and $\varphi$ on heat transfer. They found that increasing $H_{\mathrm{f}}, D, \varphi$, heat sink and heat source enhanced $N u$ ave but a rise in $H a$ deteriorated $N u$ ave. The convective flow was observed to reduce due to the presence of a magnetic field.

It can be inferred from the above studies that the MHD convection heat transfer of nanofluids in triangular cavities enhanced with $R a, \varphi$, and $m$ increased and detracted with $A R$ and $H a$. Increasing $\gamma$ was observed to enhance heat transfer for an equilateral triangle cavity filled with ferrofluids (kerosene and water-based) while the contrast was the case for an isosceles triangular enclosure containing water-based $\mathrm{Al}_{2} \mathrm{O}_{3}$ nanofluid.

\subsection{U-shaped cavity}

Ghasemi [72] employed control volume formulation to numerically investigate the MHD natural convection of a Cu-water nanofluid filled into a U-shaped cavity subjected to a magnetic field. The outside and inside curvatures of the cavity were kept at high and low temperatures, respectively, while the top faces were insulated. This work investigated the heat transfer performance of the nanofluids in the cavity considering $\varphi, A R, H a$, and $R a$. His study revealed the enhancement of heat transfer in the enclosure as $\varphi, A P$, and $R a$ increased but declined as $H a$ increased. He also noticed that an increase in $\varphi$ enhanced the total $N u_{\text {ave }}$, thermal conductivity, and heat transfer performance of the nanofluids in the enclosure. Increasing $A R$ caused the augmentation of the total $N u_{\text {ave }}$, irrespective of $R a$ values. This study reported a maximum total $N u_{\text {ave }}$ value on increasing $A R$ from 0.7 to 0.9 .

Recently, Ma et al. [117] analysed the hydromagnetic heat transfer and flow of water-based $\mathrm{CuO}$ nanofluid in a U-shaped cavity (with a fixed baffle) using the LBM scheme. The vertical walls of the cavity and the outer top walls were maintained adiabatic while the inner walls and the bottom wall were kept at low and high temperatures, respectively. The effect of $A R, R a, H a$, and $\varphi$ and Brownian motion was considered. 
A uniform magnetic field was imposed horizontally on the cavity (left). They showed that increasing $A R$ , $R a$, and $\varphi$, and decreasing $H a$ augmented $N u$ ave. It was observed that at $A R=0.6, H a=0$, and $\varphi=$ 0.05, the best heat transfer performance was achieved. An increase in heat transfer was noticed to reduce the thickness of the thermal boundary layer as $R a$ increased. In another work by Ma et al. [118] of which a similar cavity description, numerical technique, and nanofluid to that used in their previous study [117] were engaged, the influence of $\mathrm{L}_{\mathrm{b}}, \mathrm{S}_{\mathrm{b}}, R a, H a$, and $\varphi$ and Brownian motion was examined. The result revealed that the $N u$ ave was enhanced with $R a$, and $\varphi$ and deteriorated with $H a$. An increase in $\varphi$ with increasing $R a$ was observed to attenuate heat transfer but it enhanced with an increase in $H a$, which contradicted the result obtained when the battle was fixed. With battle conditions of $\mathrm{L}_{\mathrm{b}}=0.2$ and 0.4 and $\mathrm{S}_{\mathrm{b}}=0.3$, highest heat transfer enhancement was achieved. In addition, the $N u$ ave was noticed to be related to $\varphi^{-0.18}, R a^{-0.27}$, $H a^{0.08}$, and $\mathrm{e}^{1.4366 \mathrm{Sb}}$.

With the use of nanofluids in U-shaped enclosures, the hydromagnetic heat transfer was noticed to enhance with increasing $A R, R a$, and $\varphi$ and it depreciated with an increase in $H a$. However, the reverse was observed when baffle height was varied. Further research on the use of this cavity revealed the engagement of other nanofluids, most especially, the ferrofluids and the effect of the cavity and magnetic field inclination on the MHD convection heat transfer.

\subsection{T-shaped cavity}

The hydromagnetic natural convection flow and heat transfer of four nanofluids $\left(\mathrm{Cu}, \mathrm{Ag}, \mathrm{Al}_{2} \mathrm{O}_{3}\right.$, and $\left.\mathrm{TiO}_{2}\right)$ contained in an inclined T-shaped cavity were investigated using FDM [119]. Besides the vertical walls (right and left) of the cavity kept at cold temperatures (constant), the other parts of the cavity were assumed to be adiabatic. The cavity consisted of a heat source (uniform) positioned at the centre while the applied magnetic field was acting vertically download on the bottom wall of the cavity. The effects of value ranges of $\varphi, A R, H a, \vartheta, R a, B$ and $D$ were explored. They found that $N u$ was enhanced as $\varphi, D, A R, R a$, and $\vartheta$ increased but it reduced with an increase in $B$ and $H a$. An increase in $A R$ and $R a$, and a decrease in $H a, B$, and $D$ was observed to enhance convection heat transfer. The result of this work was reported to agree with a previous study.

\subsection{C-shaped cavities}

In another work, an inclined C-shaped cavity containing $\mathrm{Al}_{2} \mathrm{O}_{3}$-water nanofluid in the presence of a magnetic field was numerically examined for the natural convection phenomenon using the FVM technique [71]. The inside walls were at constant cold temperatures. The external and internal walls of the cavity were kept at high and low temperatures (constant heat flux), respectively, whereas the right vertical walls were insulated. The influence of the governing parameters of $H a, \vartheta, R a, \varphi$, and $A R$ on the heat transfer performance of the nanofluids in the cavity subject to the magnetic field was considered. On the cavity, gravity force was acting downward while the magnetic field (constant) was applied parallel to the horizontal. It was observed that the $N u_{\text {ave }}$ reduced with a raise in $H a$ for the nanofluid. At $R a=10^{5}$ and increasing $H a$ up to $H a=60$, $N u_{\text {ave }}$ was found to decline. For this work, increasing $\vartheta, A R$ and $\varphi$ were noticed to cause the augmentation of $N u$. Also, an increment in $A R$ resulted in heat transfer reduction as $\vartheta$ increased.

With a similar cavity shape and thermal boundary conditions but different orientation of the imposed magnetic field, nanofluid and governing parameters ranges compared to the work of Makulati et al. [71] and Mliki et al. [120] analysed the effect of $\varphi, \vartheta, A R, H a$ and $R a$ on the MHD natural convection heat transfer using LBM. It is pertinent to mention that the KKL correlation was utilised to evaluate the thermal conductivity and viscosity of the nanofluid. The Brownian motion effect on nanoparticles was also considered. The results showed that an increase in $\vartheta, A R$, and $\varphi$ contributed to the enhancement of $N u_{\text {ave }}$. This is in consonance with the findings of Makulati et al. [71]. It was also noticed that the fluid flow intensity and heat transfer rate dropped as the magnetic field increased. Brownian motion influence on the nanoparticles indicated the enhancement of $N u_{\text {ave }}$ as $A R$ increased and the augmentation of heat transfer with $\vartheta, A R$, and $R a$ values. At $\vartheta=\pi / 2$, the maximum impact of Brownian motion was noticed on $N u_{\text {ave }}$.

Rahimpour and Moraveji [121] employed the same cavity, thermal boundary conditions, magnetic field 
orientation, and pertinent parameters but a different nanofluid as that of Makulati et al. [71]. They examined the MHD convection of $\mathrm{Fe}_{3} \mathrm{O}_{4}$-water nanofluid in the C-configured cavity using FEM. Their result revealed that $N u$ enhanced as $R a$ and $A R$ increased which was in agreement with those of Mliki et al. [120] and Makulati et al. [71]. In addition, when $\mathrm{Ra}>10^{5}$, the $N u$ was observed to enhance with the rise of $\vartheta$, $A R$, and $\varphi$ but it detracted with $H a$ increase. A formula was proposed to predict $N u_{\text {ave }}$.

In recent work, Abedini et al. [122] explored the natural convection heat transfer in a baffled C-shaped cavity filled with water-based $\mathrm{Fe}_{3} \mathrm{O}_{4}$ nanofluid under a constant magnetic field excitation. The left vertical wall was heated and exposed perpendicularly to the magnetic field while the bottom and top walls and the right vertical walls were kept adiabatic. In addition, the inner walls of the cavity were maintained to be cold. The effect of $H a, A R, R a, L_{b}$, and $\varphi$ on the MHD convection was reported. They showed that $N u$ was improved as $A R, R a, L_{b}$, and $\varphi$ increased, and $H a$ reduced. Optimum heat transfer was achieved at $A R=0.7$ and $L_{b}=0.2$. The influence of the baffle on the thermal transport was highest at the base of the hot wall.

The use of a C-shaped cavity containing nanofluids has been shown to augment heat transfer as $A R, R a$, $\vartheta$, and $\varphi$ increased and it attenuated with $H a$ increase. The use of a baffle inside this cavity revealed the augmentation of heat transfer at an optimum value. The research gap includes the use of other nanofluids outside water based $\mathrm{Fe}_{3} \mathrm{O}_{4}$ and $\mathrm{Al}_{2} \mathrm{O}_{3}$ nanofluids and the possible inclination of the cavity.

\subsection{L-shaped cavities}

Studies are very scarce on the use of an L-shaped enclosure for the investigation of the thermo-convection behaviour of nanofluids under the influence of a magnetic stimulus. Elshehabey and Co-workers [30] utilised a differentially heated inclined L-shaped cavity containing water-based $\mathrm{Cu}$ to investigate the thermo-convection flow and heat transfer under the existence of an inclined uniform magnetic field. An FDM technique was employed in the numerical analysis while the effect of $R a, \varphi, A R, H a, \vartheta$ and $\gamma$ on the natural convection in the cavity was explored. Heat transfer and fluid flow were noticed to be substantially deteriorated on exposure to the magnetic field. The increase of $\varphi$ resulted in an appreciation of the heat transfer rate. In addition, $N u$ enhancement was observed with an increase of $R a$ and $\varphi$ whereas it reduced with an increase of $A R$ and $H a$.

\subsection{Trapezoidal cavities}

Trapezoidal-shaped enclosures containing different nanofluids under various thermal boundary conditions and different orientations of the magnetic field have been investigated for their thermo-convection flow and heat transport characteristics. A trapezoidal cavity with a heat source containing $\mathrm{Cu}$-water nanofluid under a constant magnetic field was studied using FVM [123]. The impact of $H a, \varphi$, and $R a$ was explored. Both the inclined and the left vertical sides of the cavity were kept at cold temperatures. Also, constant heat flux was supplied by the heat source mounted on the lower wall. They found that the $\mathrm{Nu}$ augmented as $\mathrm{Ha}$ increased for $R a=10^{4}$ and $10^{5}$, whereas it declined at a higher $R a$. $S_{\text {gen }}$ was observed to increase with the magnetic field but diminished with $\varphi$. It is pertinent to note that a thermal conductivity correlation outside the classical model was utilised in formulating this study.

Job and Gunakala [124] numerically studied the hydromagnetic fluid flow and heat transfer behaviours of water-based single-walled carbon nanotube (SWCNT) and $\mathrm{Al}_{2} \mathrm{O}_{3}$ nanofluids filled in a trapezoidal enclosure having a wavy bottom wall under an unsteady flow condition. The FEM technique was utilised in modelling the problem which incorporated the viscous and Joule dissipation effects. The inclined $\left(45^{\circ}\right)$ left and right sides of the cavity were kept at cold temperatures, the horizontal top and bottom walls were assumed adiabatic and heated at a hot temperature, respectively. An inspection of the influence of the model parameters ( $\varphi, A, H a$, and $t$ ) was carried out. Their results revealed that at low $H a$, the heat transfer rate of $\mathrm{Al}_{2} \mathrm{O}_{3}$-water nanofluids declined whereas it enhanced at high $\mathrm{Ha}$, and this observation is a function of $\varphi$ - In contrast, an increase in $\mathrm{Ha}$ caused a corresponding increase in heat transfer rate for SWCNT-water nanofluids. It was noticed that the addition of SWCNT nanoparticles into water enhanced heat transfer (on the bottom wall of the cavity) while increasing $\varphi$ of the $\mathrm{Al}_{2} \mathrm{O}_{3}$-water nanofluid reduced heat transfer rate. 
For the flow circulation intensity, the reverse was the case. An increase in $t$ and $A$ resulted in heat transfer rate degradation and enhancement, respectively. The SWCNT-water nanofluid was found to be a better heat transfer medium.

Job and Co-workers [125] which used the same cavity as in the work of Job and Gunakala [124] to investigate the effect of $\mathrm{Ra}$ and $\mathrm{Ha}$ on the unsteady MHD convection of the same nanofluids (water-based $\mathrm{Al}_{2} \mathrm{O}_{3}$ and SWCNT) was investigated. However, the enclosure housing the nanofluids was initially assumed to be at rest and at an isothermally cold temperature. Thereafter, the wavy bottom wall temperature was suddenly heated to an isothermally hot temperature. Their results proved to agree with those of [124] in terms of the impacts of $\mathrm{Ra}$ and $\mathrm{Ha}$ on $\mathrm{Nu}$ and heat transfer for both nanofluids.

A partially-opened trapezoidal cavity containing a $\mathrm{CuO}$-water nanofluid and exposed to an inclined uniform magnetic field was performed using an FVM technique [126]. The natural convection behaviour of the nanofluid within the cavity was inspected based on the $\gamma, H a, \varphi$, and $R a$. The lower and upper walls of the cavity were thermally insulated, the inclined side was kept at a constant high temperature while the open vertical (right) end was at a cold temperature. They reported the attenuation of heat transfer and flow rates as a result of an increase of $\mathrm{Ha}$, while the increase in $\varphi$ intensified flow and heat transfer rates. At $\gamma=\pi / 2$ (force of gravity parallel to the magnetic field), heat transfer and flow rates of the nanofluids were considerably reduced but noticed to be minimal at $\gamma=0$ (force of gravity perpendicular to the magnetic field). This indicated a non-monotonic relationship between $\gamma$ and, heat transfer and flow rates.

Bondareva and Co-workers [127] used a right-angled trapezoidal cavity containing a water-based nanofluid under an inclined uniform magnetic field to study unsteady natural convection flow, mass and heat transfer behaviour with the aid of an FDM scheme. The horizontal sides of the enclosure were insulated, the right inclined side was at a cold temperature and the left side was at a higher temperature. The non-homogeneous Buongiorno's mathematical model was utilised to incorporate several parameters such as thermophoresis and Brownian motion. Controlling parameters of $R a, \tau, H a, \gamma, A R$, and $L e$ were explored and visualised using isoconcentration. They showed that augmenting $R a$ and $\gamma$ caused $N u$ and $S h$ to intensify but they detracted as $A R$, $H a$ and $L e$ increased. At low $H a$ and $L e$, nanoparticles distribution was observed to be non-homogeneous, thus, requiring a similar model for formulation.

In a recent study by Astanina and Co-workers [128], an open trapezoidal cavity containing water-based $\mathrm{Fe}_{3} \mathrm{O}_{4}$ (full) and a permeable layer under an inclined uniform magnetic field stimulus was investigated for the natural convection and entropy generation using FDM. The top of the cavity was opened and kept isothermally cold while the bottom, inclined right and upper part of the inclined left walls were kept adiabatic. The lower part of the inclined left wall was heated to a length equal to the depth of the porous layer in the cavity. The Brinkman-extended Darcy model for porous layer was incorporated in the simulation while the role of pertinent parameters of $\gamma, \mathrm{Ha}, \varphi$, and $\delta$ was examined. Their results proved that the rate of heat transfer, nanofluid flow, and $S_{\text {gen }}$ diminished as Haand $\delta$ increased. At $\gamma=3 \pi / 4$, maximum values of heat transfer, nanofluid flow, and entropy generation were attained while the minimum values occurred at $\gamma=\pi / 4$.

Using this cavity type and different nanofluids, heat transfer was generally observed to enhance as $A R, A$, $R a$, and $\varphi$ increased and as $t, \delta$, and $H a$ decreased. The reverse was reported for $R a$ [123], $H a$ [124], and $\varphi[124]$ whereas optimum heat transfer was recorded for $\gamma[128]$.

\subsection{Open cavities}

The containment of different nanofluids in open cavities subjected to various thermal boundary conditions and magnetic field stimulations have been studied for the characteristics of heat transfer and flow. An open cavity filled with $\mathrm{Al}_{2} \mathrm{O}_{3}$-water nanofluid in the presence of a magnetic field was investigated using LBM [129]. The influence of $\varphi, \psi, H a$ and Rawas explored. The cavity was opened and cooled on the vertical right and subjected to sinusoidal heating on the vertical left with both horizontal walls kept adiabatic. A uniform magnetic field was applied axially on the cavity from the left side. They reported that the heat transfer rate was augmented when $R a$ increased and it reduced with an increase in $H a$. The rate of heat transfer rate was seen to augment with an increase in $\varphi$ for all values of $\psi$ and the maximum effect of nanoparticles addition 
was attained at $\psi=\pi / 4$ for $R a=10^{5}$. In addition, the increment in $\psi$ led to heat transfer enhancement for all values of $H a$ with the peak $\psi$ [?] $\mathrm{p} / 2$ and $R a=10^{5}$.

In an earlier study, the influence of $\varphi, R a$, and $H a$ on the MHD natural convection of a water-based $\mathrm{Al}_{2} \mathrm{O}_{3}$ nanofluid in an open cavity was performed with the aid of LBM [130]. An examination of an identical cavity to that studied by Mejri and Mahmoudi [129] but with the left vertical wall maintained isothermally hot was performed. The effect of $R a, \varphi$, and $H a$ on the heat transfer was found to be analogous to the result of Mejri and Mahmoudi [129], despite the difference in the heating method. In addition, the impact of $\varphi$ was significant for all $H a$ at $R a=10^{6}, H a=30$ for $R a=10^{4}$ and $H a=60$ for $R a=10^{5}$.

In the presence of an inclined uniform magnetic field, the MHD convection of an open cavity occupied with $\mathrm{Cu}$-water nanofluid was studied using LBM [131]. Both the horizontal sides of the cavity were thermally insulated whereas the vertical (left) side was sustained at a high temperature. The open end of the cavity (vertical left) serving as the entrance to the nanofluid was isothermally cold. Monitoring of the pertinent parameters $(\gamma, \varphi, H a$ and $R a)$ as they affect heat transfer and flow was carried out. They demonstrated similar results as most studies stating the increase in $N u$ with $R a$ but a drop with $H a$. Also, owing to $R a$ and $\mathrm{Ha}, \varphi$ was noticed to have an appreciable impact on the heat transfer and $N u$. At high $R a, N u_{\text {ave }}$ was enhanced with $\gamma$.

A partially-opened porous cavity (with a wavy wall) containing $\mathrm{Cu}$-water nanofluid and exposed to an isothermal corner heater was investigated by Sheremet et al. [132]. The effect of the governing parameters $(\varphi, \gamma, H a$, and $R a)$ on the MHD convection heat transfer and flow was explored. The wavy left wall of the cavity was kept isothermally cold. The heating of the cavity was at the right bottom corner with the bottom wall thermally insulated. They observed heat transfer augmentation in the enclosure to depend on Raincrease and a decline in $\mathrm{Ha}$. The convective flow was observed to intensify with an increase in $\gamma$ from 0 to $\pi / 2$ and attenuated as $H a$ and $\varphi$ increased. Under magnetic field stimulation, increasing $\varphi$ was noticed to cause a reduction in the transfer of heat. A non-monotonic influence was found for heat transfer due to $\varphi$ and $\gamma$ increment.

As a build-up on the work of Sheremet et al. [132], Bondareva et al. [133] analysed the effect of $H a, \varphi$, $\gamma, \vartheta$, and $R a=10^{3}$ on the thermo-convection flow and heat transfer of a $\mathrm{Cu}$-water nanofluid filled into an inclined version of the cavity studied by Sheremet et al. [132], though with $A R=4$. Unique to this work was the use of heatlines as a visualisation method in addition to the conventional isotherm patterns and streamlines. The result revealed a reduction in both the rate of heat transfer and convective flow intensity for a collective increase in $\mathrm{Ha}$ and $\gamma$, and $\vartheta$ and $\mathrm{Ha}$. The influence of the magnetic field may be responsible for this. At $\vartheta=\pi / 2$, the $N u$ was maximum indicating orthogonality between gravity and Lorentz force, which was in agreement with the result of Sheremet et al. [132] that engaged partially-opened porous cavity, though not inclined.

Sheikholeslami [134] applied the LBM technique to analyse the effect of $\varphi, R a, H a$ and $D a$ on the MHD convection of a water-based $\mathrm{CuO}$ nanofluid contained in an open porous cavity. The enclosure's right vertical boundary was opened, the left vertical wall was heated, and the horizontal walls were thermally insulated. The Brownian motion of the $\mathrm{CuO}$ nanoparticle was accounted for by utilising KKL model in the problem formulation. He observed the enhancement of $N u$ with $\varphi, R a$ and $D a$ and its deterioration with $H a$. The increment of $D a$ and $\varphi$ was also found to augment convective heat transfer. A correlation was derived for $N u_{\text {ave }}$ prediction.

In the work of Kolsi et al. [135], a 3-dimensional open cubic cavity with an inclined fin containing a CNT water-based nanofluid under magnetic field stimulus was employed to analyse the hydrothermal behaviour. The right vertical side of the enclosure was opened, the left vertical side was isothermally heated while the rest of the sides were thermally insulated. A finite length fin was inclined inside the enclosure whereas the external magnetic field was applied from the left vertical side of it. Controlling parameters of $\vartheta_{\varphi}, \varphi, H a$ and $R a$ were inspected. They discovered that heat transfer was enhanced when $\varphi$ and $R a$ increased and $H a$ reduced. Maximum and minimum heat transfer was attained at $\vartheta_{\varphi}=180^{\circ}$ and $270^{\circ}$, respectively. They 
concluded that all the controlling parameters can be utilised to passively control nanofluid flow and heat transfer.

As can be noticed from the published works on the employment of open cavity to study the natural convection heat transfer performance of nanofluids under magnetic field existence, heat transfer enhanced with ?, $\gamma, D a$ , and $R a$ increase and reduced with Haincrease. At an optimal value of $\vartheta_{\mathrm{f}}$, the highest heat transfer was achieved. This indicates that the use of fin as an active method of heat transfer enhancement has a positive influence on heat transfer. The engagement of diverse nanofluids and their impact on the MHD convection heat transfer is opened for future study.

\subsection{Curved cavities}

The application of nanofluid contained in curved-shaped cavities has been investigated for the hydrothermal heat transfer behaviour. Sheikholeslami and Rokni [136] applied the LBM scheme to analyse the natural convection flow in a permeable curved enclosure occupied with a water-based $\mathrm{CuO}$ under magnetic field influence. The semi-circular walls were differentially heated, and a uniform magnetic field was imposed on the left side of the cavity. Brownian motion impact of the $\mathrm{CuO}$ nanoparticles was implemented by using the KKL model. Pertinent parameters of $\varphi, R a, D a$, and $H a$ were considered. They observed that as $R a$ and $\mathrm{Da}$ increased; the $\mathrm{Nu}$ ave was augmented, and it diminished as $\mathrm{Ha}$ increased. The increase of Lorentz forces was noticed to cause the attenuation of convection flow which enhanced with $R a$.

The natural convection characteristics in a double-wavy curved enclosure occupied with $\mathrm{Fe}_{3} \mathrm{O}_{4}$-water nanofluid and subjected to a magnetic field source and thermal radiation performed by Sheikholeslami and Shamlooei [137]. The base and inclined top sides of the cavity were assumed adiabatic while the right wavy side was at a cold temperature. Constant heat flux was supplied by the left wavy wall with the external magnetic field source applied near the wall. Using the CVFEM technique, the effect of controlling parameters of $R d, \varphi, R a$ and $H a$ on the cavity was investigated. They showed that in the presence of the magnetic field, the thermal radiation weakened causing deterioration of convective heat transfer, but it intensified in the absence of the magnetic field leading to heat transfer augmentation. In addition, the depth of the thermal boundary layer was a direct function of $H a$ and $R d$, and an inverse function of $\varphi$ and $R a$. $N u$ was observed to enhance with $R d$ and diminished with $H a$. The model formulation engaged a viscosity correlation (temperature and magnetic field dependent) instead of the classical model utilised by most studies.

Sheikholeslami and Ganji [138] applied the CVFEM technique to study the influence of thermal radiation on the MHD convection of a water-based $\mathrm{Fe}_{3} \mathrm{O}_{4}$ nanofluid in a permeable curved cavity. The curved and horizontal sides of the cavity were assumed cold while the vertical wall was maintained hot. An external magnetic source was imposed on the cavity from the left bottom side. The impacts of $\varphi, R a, R d$, and $\mathrm{Ha}$ on the MHD convection were explored. The obtained results were in agreement with a similar study carried out by Sheikholeslami and Shamlooei [137] which considered a double wavy-curved cavity. They indicated that as $\varphi$ and $R a$ increased temperature gradient appreciated nonetheless it declined as $H a$ and $R d$ increased. It was found that increasing Lorentz forces enhanced the thickness of the thermal boundary layer and attenuated the flow. At higher buoyancy force, the effect of $R d$ was found to be significant. A correlation was also proposed to calculate $N u_{\text {ave }}$.

Sheikholeslami and Ganji [139] analysed the MHD natural convection behaviour of a $\mathrm{Fe}_{3} \mathrm{O}_{4}$-water nanofluid in a curved cavity with a hot inner squared shape using CVFEM. The outer circular wall of the cavity was kept cold, the outer vertical and horizontal walls were insulated while the inner vertical and horizontal walls (square) were maintained at hot temperatures. The impact of nanoparticle $\varphi, r_{i n}, H a$, and $R a$ on the MHD natural convection was explored. The result showed the attenuation of flow velocity and temperature gradient as Haincreased. They noticed that an increase in $r_{i n}$ was found to decrease the thickness of the thermal boundary layer while increasing Lorentz forces favoured the reduction of $N u$ which augmented as buoyancy forces increased. In addition, $N u_{\text {ave }}$ was enhanced as $\varphi$ increased. They proposed a correlation to determine $N u_{\text {ave }}$ as a function of $r_{i n}, \varphi, H a$, and $R a$. 
A permeable curved enclosure filled with $\mathrm{Fe}_{3} \mathrm{O}_{4}$-water nanofluid and subjected to an external magnetic field was simulated for the effect of $\varphi, H a, D a$, and $R a$ on the natural convection characteristics using CVFEM [140]. The vertical side (left) of the cavity was considered hot while the arc surface and bottom side were kept cold. He observed that a decline of $R a$ and $D a$, and an increase of $H a$ led to heat transfer intensification. However, the appreciation of $\varphi, D a$, and $R a$ enhanced $N u$. The exposure of the cavity-filled nanofluid to a magnetic field caused a reduction of fluid motion leading to an increase in the thickness of the thermal boundary layer. It was also noticed that as $\varphi, R a$ and $D a$ increased and $H a$ decreased, the temperature gradient was augmented.

Generally, studies on the MHD convection of nanofluids in this type of enclosure revealed heat transfer augmentation with $\varphi, D a$, and $R a$, and attenuation with $H a$ and $R d$.

\subsection{Complex cavities}

The complexity of cavities was studied for the MHD convection of nanofluids filled into them. Cho [141] employed a complex-wavy enclosure to investigate the effect of $\varphi, \lambda_{\mathrm{w}}, A, H a, R a$ and $E c$ on the hydromagnetic behaviours (heat transfer and entropy generation) of a water-based $\mathrm{Cu}$ nanofluid using FVM technique. The smooth horizontal sides of the cavity were sustained adiabatic while the wavy right wall was assumed to be isothermally cold. The wavy left side was heated at a constant heat flux and subjected to a uniform external magnetic field. Their findings revealed the improvement of $N u$ with $R a$ (high values) and $\varphi$ and its deterioration with $H a$ and $A$. However, the $S_{g e n}$ increased with $R a$ (high values), $H a$ and $A$, and $\varphi$ showed no effect. At an optimum value of $\lambda_{\mathrm{w}}$, minimum $S_{\text {gen }}$ and maximum heat transfer were achieved. In addition, the $E c$ was noticed to augment with $H a$ and $\varphi$ but detracted with $B e$.

Sheikholeslami et al. [142] performed an investigation (CVFEM) into the MHD convection performance of a complex cavity occupied with a water-based $\mathrm{Cu}$ nanofluid. The outer surface of the enclosure was assumed to be isothermally cold while the surface of the inner sinusoidal cylinder was kept hot. A horizontal uniform magnetic field was imposed externally on the cavity. The influence of $\varphi, N, H a$, and $R a$ was explored. They noticed the augmentation of $N u$ with $\varphi, R a$, and $N$ and the reverse with $H a$. Maximum heat transfer augmentation was attained at $H a=20$ for $R a=10^{4}$ and $H a=60$ for $R a=10^{5}$.

The influence of $R d, \varphi, H a$ and $R a$ on the natural convection characteristics in a complex cavity containing $\mathrm{Fe}_{3} \mathrm{O}_{4}$-water nanofluid under the existence of thermal radiation and inclined magnetic field source was simulated using CVFEM [143]. The outer wall of the enclosure was sustained isothermally cold while the wall of the inner elliptic cylinder was at a constant heat flux. The inclined magnetic field was imposed on the left side of the enclosure. The formulation of this problem employed thermal conductivity and viscosity correlations which accounted for the shape of the nanoparticles and magnetic field. They found that the platelet-shaped nanoparticle having the highest shape factor yielded the highest $N u$. Heat transfer within the cavity was observed to rise with $R d$ and $R a$, which declined as $H a$ increased. This finding agreed with the work of [137] in which a curved cavity was used. The increase in temperature gradient and $R a$ caused $\mathrm{Nu}$ augmentation while the reverse was the case with $\mathrm{Ha}$ increase.

In the presence of thermal radiation, Sheikholeslami [144] applied CVFEM to examine the influence of $R a$, $R d, \varphi, H a$, and $\vartheta$ on the MHD convection in a complex enclosure containing water-based $\mathrm{Fe}_{3} \mathrm{O}_{4}$ nanofluid with an inclined inner elliptic cylinder. The outer wall of the enclosure was assumed to be cold while the inner wall supplied heat at a constant heat flux. The radiation source term was considered using the energy equation. A viscosity correlation dependent on temperature, magnetic strength and $\varphi$ was used in the formulation of the analysis. His results showed the enhancement of $\mathrm{Nu}$ with $\vartheta$ which decreased with $\mathrm{Ha}$ . Also, he noticed that increasing the magnetic field caused heat transfer to diminish but it augmented with increasing $R d$. The temperature of the inner wall was found to increase with $R d$ and declined with $R a$. In addition, the author developed a correlation for the estimation of $N u_{\text {ave }}$ as a function of the studied governing parameters.

Sheikholeslami and Rokni [145] applied CVFEM to investigate the MHD convection flow of a water-based $\mathrm{CuO}$ nanofluid inside a permeable complex cavity with a hot inner sinusoidal cylinder. The outer circular 
and inner (sinusoidal) cylinders were maintained at low and high temperatures, respectively. The magnetic field source was located and applied axially at the left side of the enclosure. Both the Darcy model and KKL correlation were included in the model formulation and the impacts of $R a, N, H a$, and $\varphi$ on the convective heat and flow were examined. They found that increasing $R a, N$, and $\varphi$ enhanced heat transfer while the rise of $H a$ reduced it. In addition, it was noticed that at high values of $H a$, the effect of increasing $\varphi$ was significant. A correlation for the estimation of $N u_{a v e}$ was proposed. A similar result was reported by Sheikholeslami et al. [142] for $H a, R a, N$ and $\varphi$ though with a different nanofluid and cavity configuration.

Sheikholeslami and Shehzad [146] carried out the analysis of the hydromagnetic behaviour of a water-based $\mathrm{Fe}_{3} \mathrm{O}_{4}$ nanofluid in a porous complex-shaped cavity by applying CVFEM technique. The wavy outer cylinder wall of the enclosure was kept isothermally cold while the inner elliptic cylinder wall was maintained at a constant heat flux. A constant magnetic field was imposed axially on the left side of the cavity. Non-Darcy model and a viscosity correlation dependent on the magnetic field were incorporated into the simulation. Controlling parameters explored were $R a, D a, H a$, and $\varphi$. They proved that heat transfer was enhanced with $R a$ and $D a$ increase, but it diminished with $H a$ rise. It was also noticed that the magnetic field increment caused the reduction of nanofluid flow and augmentation of thermal boundary layer thickness.

Recently, Dogonchi et al. [147] analysed the MHD convection heat and flow behaviour in a triangle-shaped complex cavity containing $\mathrm{CuO}$-water nanofluid. The diagonal walls of the cavity were kept cold while the base horizontal and part of the wavy walls were thermally insulated. Heating was provided by the upper and remaining part of the wavy wall not insulated. A uniform magnetic field was imposed on the left of the cavity. $H a, \varphi, R a$, and $m$ were governing parameters considered in the work while the KKL correlation for the effective viscosity and thermal conductivity was incorporated into the model formulation. They showed that heat transfer (local and average) was enhanced as $R a$ increased and reduced as $H a$ surged. Deterioration of $N u$ ave by $30.37 \%$ and $32.95 \%$ as $\mathrm{Ha}$ increased from $0-50$ and at $\varphi=0.02 \mathrm{vol} . \%$, respectively, was observed. This was linked to the improvement of thermal and electrical conductivity with a rise in $\varphi$. However, at $\varphi$ $=0.02 \mathrm{vol} . \%, \mathrm{~m}=5.7$ (platelets) and $H a=25$, the $N u$ ave was augmented by $3.14 \%$.

Vo et al. [148] studied the thermo-convection in a porous complex cavity filled with water-based $\mathrm{Al}_{2} \mathrm{O}_{3}$ nanofluid in the presence of magnetic field stimulation using CVFEM. The inner surface of the cavity supplied a constant heat flux while the outer surface was kept cold. The magnetic field was imposed on the vertical (left) wall of the cavity. Brownian motion was incorporated into the model formulation. They prove that increasing $R d, m, R a$ and reducing $H a$ enhanced $N u$ ave.

The influence of governing parameters of $H a, \varphi, R a, A, R d, D a$, and $m$ on the MHD convection of a porous complex cavity filled with water-based $\mathrm{CuO}$ nanofluid was studied by Dogonchi et al. [149] using CVFEM technique. The cavity was heated using the inner waxy circular cylinder while the outer part was maintained at a lower temperature. Magnetic field stimulus was applied at an angle to the cavity. They proved that increasing $R a, R d$, and $D a$ enhanced the $N u$ ave while an increment in $H a, \varphi$, and $A$ caused depreciation of $N u$ ave. Like other previous studies on the shape factors of nanoparticles, the platelet $(\mathrm{m}=$ 5.7) was found to enhance heat transfer than other shapes.

It can be generally observed that the engagement of this type of cavity for hydromagnetic behaviour of nanofluids showed the improvement of heat transfer as $R a, R d, D a, N, ?, m$, and $\vartheta$ increased and its reduction as $A$ and $H a$ surged. An exception was noticed by Dogonchi et al. [149] where heat transfer was detracted with an increase in?.

\subsection{Prism cavity}

Parvin and Akter [150] analysed the MHD natural convection of a prism-shaped cavity containing $\mathrm{Al}_{2} \mathrm{O}_{3}$ water-based nanofluid by applying the FEM scheme. The inclined sides of the cavity were assumed to be isothermally cold; the vertical walls were insulated while the bottom wall was subjected to sinusoidal heating. A magnetic field was horizontally imposed on the cavity from the right side. The influence of $\mathrm{Ha}$ , $R a$ and ? on the nanofluid heat transfer was examined. They observed that increasing $H a$ has a negative impact on the rate of heat transfer while $R a$ and ? enhanced it. 


\subsection{Rhombic cavity}

The effect of $\varphi, R a, \vartheta_{\mathrm{r}}$, and $H a$ on the hydromagnetic heat transfer and entropy generation of Cu-water in a rhombic cavity was examined by Dutta et al. [151] using FEM technique. The two diagonal walls of the cavity were maintained adiabatic while the bottom and top walls were kept at high and low temperatures, respectively. A uniform magnetic field was applied axially on the left side of the cavity. The results showed that the heat transfer rate was enhanced as $H a$ reduced for high $R a$ values. At $R a=10^{3}$ and $10^{4}$, heat transfer was noticed to augment with $\vartheta_{\mathrm{r}}$ for all $H a$ values, but detraction was found when $R a=10^{5}$ and $10^{6}$. Increasing $\varphi$ was observed to augment $N u$ ave by $6.5 \%(H a=0)$ and $0.88 \%(H a=100)$ at $R a=10^{5}$ and by $7.12 \%(H a=0)$ and $3.11 \%(H a=100)$ when $R a=10^{6} . S$ gen was reduced as $H a$ increased (for all $R a$ values) and $\vartheta_{\mathrm{r}}$ increased.

\subsection{MHD natural convection in different enclosures (analytical)}

As one of the methods for investigating the MHD convection of nanofluids in cavities, the analytical technique has been reported by very few authors. Benos and Sarris [152] analysed the thermo-convection heat and flow behaviour in a shallow rectangular cavity containing $\mathrm{Cu}$-water under a uniform magnetic stimulus using a matched asymptotic expansions method. The top and bottom walls of the cavity were kept adiabatic while the vertical walls were maintained isothermally. Also, the entire walls of the cavity were electrically insulated. Heating was provided using a volumetric internal heat source. KKL correlations (viscosity and thermal conductivity) and Brownian motion were engaged in the analysis. The influence of $H a, \varphi, \mathrm{r}_{\mathrm{p}}$, and $R a_{\mathrm{s}}$ was studied. They demonstrated that convective flow was enhanced by increasing internal heating. It was observed that the $N u$ ave enhanced as $R a_{\mathrm{s}}$ and $\mathrm{r}_{\mathrm{p}}$ increased but it attenuated with $\mathrm{Ha}$. Heat transfer enhanced as $\varphi$ increased in the absence of the magnetic field stimulus but deteriorated in the presence of the magnetic field. Increasing the magnetic field and reduction of $r_{p}$ were noticed to cause the dominance of conduction over convection.

In the work of Benos et al. [153], an identical cavity and similar governing parameters' $\left(H a, \mathrm{r}_{\mathrm{p}}\right.$, and $\left.R a_{\mathrm{s}}\right)$ and range of values to that studied by Benos and Sarris [152] were theoretically investigated for the MHD heat and flow performance of SWCNT-water nanofluid in the cavity. Benos et al. [153] incorporated a different model for the estimation of viscosity, electrical and thermal conductivity that considered the effect of nanolayer $\left(t_{h}\right)$ and did not take account of Brownian motion when compared to the work of Benos and Sarris [152]. In addition, Benos et al. [153] examined the influence of shape factor on the MHD convection. They proved that $H a$ and $R a$ s contribute significantly to heat transfer and flow augmentation. $N u$ ave was found to deteriorate as $\varphi, \mathrm{t}_{\mathrm{h}}, m$, and $H a$ increased, and it appreciated with an increase in $R a_{\mathrm{s}}$ and $\mathrm{r}_{\mathrm{p}}$. Also, heat transfer enhancement was noticed as $m$ tends to be a complete sphere and $a_{\mathrm{h}} \mathrm{t}_{\mathrm{h}} / \mathrm{m}$ reduced.

The incorporation of $t_{\mathrm{h}}$ and $m$ into the analysis of Benos et al. [153] as against the Brownian motion introduced by Benos and Sarris [152] which improved heat transfer is the sole disparity in the findings of both studies. This revealed that the introduction of Brownian motion is not adequate to analyse MHD convection heat and flow in the rectangular shallow cavity and that $t_{h}$ and $m$ of the nanofluid used in the cavity is very significant.

\subsection{MHD natural convection of hybrid nanofluids in different enclosures}

The emerging trend in the study of heat transfer using nanofluids has led to the use of hybrid nanofluids. In a recent work by Ashorynejad and Shahriari [154], the hydrothermal characteristics of a hybrid nanofluid (water-based $\mathrm{Al}_{2} \mathrm{O}_{3}-\mathrm{Cu}$ ) filled into a waxy-walled open cavity in the presence of a uniform magnetic field were investigated using LBM scheme. Both the horizontal sides of the cavity were sustained adiabatic, the left wall was wavy and sinusoidally heated while the remaining wall was an open boundary kept at ambient temperature. Pertinent parameters explored were $\mathrm{Ha}, \varphi, \psi$, and $R a$. Their findings demonstrated the attenuation of $N u$ as $H a$ increased and its enhancement as $R a$ and $\varphi$ increased. $N u$ was enhanced as $\varphi$ and $\psi$ increased for $R a=10^{5}$. The highest heat transfer augmentation was attained at $H a=90$ with the lowest at $H a=30$. 
Rashad and Co-workers [155] numerically studied the MHD natural convection of a water-based hybrid nanofluid $\left(\mathrm{Cu}-\mathrm{Al}_{2} \mathrm{O}_{3}\right.$ /water) inside a triangular cavity heated from the bottom wall with the use of FDM. The inclined right wall of the enclosure was isothermally cold while the left vertical side was thermally isolated. The bottom wall was partly insulated and partly heated centrally at a constant heat flux. A constant magnetic field was imposed on the cavity from the left side. Controlling parameters of $\mathrm{Ra}, \mathrm{B}, \mathrm{Ha}$ $, D, Q$ and $\varphi$ were explored. They demonstrated that the heat transfer rate was augmented with an increase in $D$ and $R a$, and the reduction of $B$ but deteriorated with the rise of $Q$ and $H a$. Increasing $\varphi$ was found to be pronounced when $R a$ was low, $H a$ was high and when $D$ and $B$ increased. In comparing the heat transfer augmentation of the hybrid nanofluid with those of mono-particle nanofluids $\left(\mathrm{Al}_{2} \mathrm{O}_{3}\right.$-water and $\mathrm{Cu}$-water), no noticeable effect was observed.

Recently, Mehryan et al. [156] used FEM to analyse the thermo-convection in a double porous inverted T-shaped cavity saturated with $\mathrm{MWCNT}-\mathrm{Fe}_{3} \mathrm{O}_{4} /$ water nanofluid under an inclined magnetic field. The vertical walls of the bottom chamber of the cavity and the top wall of the top chamber were kept adiabatic whereas the top walls of the bottom chamber and vertical walls of the top chamber were maintained cold. The bottom wall of the bottom chamber of the cavity was used to provide heat. The uniform magnetic field at varying angles was imposed on the cavity. The impact of $\varphi, \delta_{0}, \mathrm{e}_{\mathrm{r}}, \gamma, \mathrm{H}_{\mathrm{r}}$, and $\mathrm{K}_{\mathrm{r}}$ on heat transfer was examined. The result showed that increasing $e_{r}$ and $K_{r}$ and decreasing $\delta_{0}$ and $H_{r}$ caused improvement of heat transfer in the cavity. $N u$ was enhanced when $\delta_{0}$ and $K_{\mathrm{r}}$ were increased. Highest $N u$ ave was observed at $\gamma=140^{\circ}$ and when $\delta_{0}=0$ for all $\gamma$ values. Also, the convection flow in the cavity was enhanced with an increase in $\mathrm{e}_{\mathrm{r}}$.

It is worth mentioning that the studies on the use of $\mathrm{Cu}-\mathrm{Al}_{2} \mathrm{O}_{3} /$ water and MWCNT- $\mathrm{Fe}_{3} \mathrm{O}_{4} /$ water nanofluid (hybrid nanofluid) in non-square cavities for the hydromagnetic behaviours employed modified classical models for the estimation of the thermo-physical properties (see Table 4). This is a clear indication of the need to obtain the experimental data of thermophysical properties and formulate the corresponding correlations, and consequently engage such in the modelling of the numerical study.

\subsection{Future research focus}

Owing to the availability of literature on the MHD natural convection characteristics of nanofluids in nonsquare enclosures in the public domain, we have observed that most of the publications on this subject are majorly numerical in nature with few and none investigated using experimental and theoretical methods (see Tables 1 and 2). Obviously, the experimental studies on the MHD convection of nanofluids in non-cavities are very important and there is an urgency for researches to be conducted in this regard. The application of numerical and theoretical methods alone should not be the only method for studying the hydromagnetic behaviours of nanofluids in non-square cavities. The experimental method along with the theoretical and numerical techniques are very important too. A combination of results from numerical, experimental and theoretical studies on this subject would provide a better explanation and a deeper understanding of the respective findings. Consequently, the existing gaps in outcomes emanating from these methods of study would be bridged.

Basically, two types of base fluids (water and kerosene), eight types of nanoparticles (Co, $\mathrm{Cu}, \mathrm{CuO}, \mathrm{Al}_{2} \mathrm{O}_{3}$, $\mathrm{Fe}_{3} \mathrm{O}_{4}, \mathrm{Ag}, \mathrm{TiO}_{2}$, and SWCNT), and a type of nanoparticles $\left(\mathrm{Cu}-\mathrm{Al}_{2} \mathrm{O}_{3}\right)$ have been employed in the formulation of nanofluids utilised in the non-square cavities reviewed in this study (Tables $1-3$ ). With only two studies engaging kerosene as a base fluid and the rest using water, there is the need to employ other conventional base fluids such as ethylene glycol, propene glycol, and engine oil. Progress in research has revealed the utilisation of ionic, eutectic, and bio-sourced (bio-glycol) base fluids in nanofluid preparation which is yet to be studied theoretically, numerically and experimentally for the MHD natural convection of nanofluids in non-square enclosures under magnetic field stimulation $[61,157]$. The use of nanoparticles other than those mentioned above, especially, the bio-derived (green), spinel, magnetic and hybrid nanoparticles should be exploited in future studies. Recently, Giwa et al. [158] experimentally studied the thermo-convection heat transfer of hybrid nanofluids $\left(\mathrm{Al}_{2} \mathrm{O}_{3}-\mathrm{MWCNT}\right.$ /water $)$ in a square cavity without the influence of the magnetic field, which is considered a great stride in experimenting hybrid nanofluids. 
In this present work, the reviewed publications obviously reveal that most authors employed theoretical models for estimating the thermo-physical properties of the engaged nanofluids with a few using experimental data derived correlations. The classical models and the correlations used in the reviewed publications for this present paper are provided in Table 4. Recently, Astanina et al. [159] investigated the discrepancy in the result of the MHD convection heat transfer in a square cavity when theoretical models and experiment sourced correlations were utilised in the evaluation of the thermal properties of nanofluids contained in a cavity. They showed that the theoretical models overestimated the heat transfer performance. Although the discontinued use of theoretical models in numerical studies has been under thoughtful public deliberation for a while, yet it is still being engaged by most authors to date. It is becoming clear owing to current research trend in the use of hybrid, green, and ionic nanofluids that the classical/theoretical models and even to an extent the experimental data-derived correlations for specific nanofluid types cannot be effectively utilised to model future numerical works on the MHD convection in cavities for dissimilar nanofluids. Personally, we are of a strong opinion that experimentally obtained correlations for a nanofluid type must be used for the same nanofluid since it is apparent that nanofluids differ in thermophysical properties from one another.

The no-slip postulation (single-phase) made for nanofluids (solid-liquid blends) was considered by most of the literature on the hydromagnetic behaviours of nanofluids in non-square cavities as against the two-phase postulation. Controversy regarding which of the two approaches models nanofluids better and provides accurate results is still ongoing. However, the two-phase approach appears to be a better assumption for modeling the MHD convection as it better imitates the reality of the solid-liquid phenomenon of nanofluids. Of the reviewed papers in this work, only six engaged the slip condition assumption (see Table 1), which calls for more studies using this condition. The Newtonian or non-Newtonian behaviour of nanofluids as it depends on the type of base fluids used and the extent of dispersion of nanoparticles should be mentioned and considered in the problem formulation as most of the reviewed literature failed in this regard. In this present work, few studies described the behaviours of nanofluids investigated as being Newtonian and none considered a non-Newtonian nanofluid.

Additionally, most studies on the MHD natural convection flow conditions of nanofluids in non-square cavities have been on steady flow conditions with only Bondareva et al. [127] and Sheremet et al. [124] having considered the unsteady flow condition of nanofluids. The transient flow condition and more of unsteady flow should be further explored as they are of practical importance in engineering applications. At present, only two studies have conducted natural bioconvection in square cavities $[65,66]$ and none is yet to be studied in non-square cavities for thermo-bioconvection and MHD bioconvection of nanofluids. Hence, the future opportunity to investigate the MHD bioconvection in various shapes of cavities and using different types of nanofluids, most especially the emerging ones. Furthermore, the use of other visualisation methods such as heatlines, iso-surface, isoconcentrations, and particle trajectory, heat functions and velocity vector outside the conventional isotherms and streamlines should be presented in future studies.

\subsection{Conclusion}

A review of the MHD natural convection of nanofluids in non-square cavities has been conducted in which the majority of the studies are based on the numerical approach and very few on theoretical methods and none on the experimental approach. It has been observed that heat transfer enhancement deteriorates in the presence of the magnetic field, except in very few cases where it either augments at certain values or enhances with an increasing magnetic field. Depending on the shape of the cavity and other parameters such as the mode of heating and thermal boundary conditions, increasing $\vartheta$ and $D a$ are found to largely augment heat transfer in the cavities while attenuation is mostly reported for $\gamma$ increment. The results are highly reliant on several variables such as the orientation and application of the thermal boundary conditions, cavity types, correlations or models (used for estimating the thermophysical properties), type and orientation of the magnetic fields, use, type and number of heaters, temperature distribution methods, and exposure of nanofluids to radiation, viscous dissipation effects etc. The choice of classical models or experimental-sourced correlations is observed to be critical to the modeling of the MHD convection in non-square cavities and consequently, the extent of accuracy of the obtained results. 


\section{Acknowledgement}

The funding received from the National Research Foundation of South Africa under the Renewable and Sustainable Energy Doctoral Scholarships is hereby acknowledged and appreciated.

\section{Nomenclature}

$A$ - amplitude of wavy wall/surface

$a_{e c}$ - major axis of elliptic cylinder

$A R$ - aspect ratio

$B$ - dimensionless heat source/sink length

$\mathrm{Br}$ - Brownian motion

$C_{p}$ - heat capacity at constant pressure

$d$ - diameter

$D$ - dimensionless heat source/sink location

$D a$ - Darcy number

$D a_{\mathrm{r}}-$ Darcy number ratio

$D_{f}$ - dimensionless fin location

$e$ - viscous dissipation parameter

$E c-$ Eckert number

$H a$ - Hartmann number

$H_{\mathrm{f}}$ - dimensionless fin height

$H_{\mathrm{r}}$ - ratio of dimensionless convection coefficient at the interface of nanofluid and solid and phases

$K_{p}$ - partition thermal conductivity

$K_{r}$ - modified relative thermal conductivity ratio

$\mathrm{L}_{\mathrm{b}}$ - baffle length

$L e$ - Lewis number

$m$ - shape factor

$M n$ - magnetic number

$N$ - enclosure undulation number

$n$ - power index

$\mathrm{N}_{\mathrm{bt}}$ - ratio of Brownian motion to thermophoretic diffusivities

Nhs - solid-nanofluid interface heat transfer parameter

$\mathrm{Nu}$ - Nusselt number

$P e$ - Peclet number

$Q$ - heat generation parameter

$R a$ - Rayleigh number

$R a_{\mathrm{s}}$ - scaled Rayleigh number 
$R d$ - radiation parameter

$r_{i n}$ - inner cylinder size/radius

$\mathrm{r}_{\mathrm{p}}$ - nanoparticle radius

$S$ - entropy

$\mathrm{S}_{\mathrm{b}}$ - baffle position

$S_{g e n}$ - entropy generation

$S h$ - Sherwood number

$S_{\text {tgen }}$ - total entropy generation

$t$ - time in second

$T_{f r}$ - Freezing temperature of base fluid

$\mathrm{t}_{\mathrm{h}}$ - nanolayer thickness

$u_{b r}-$ Brownian motion velocity

$W_{\mathrm{f}}$ - dimensionless fin height

\section{Greek symbols}

$$
\begin{aligned}
& a-\text { thermal diffusivity } \\
& \beta \text { - thermal expansion coefficient } \\
& \gamma \text { - angle of rotation of magnetic field } \\
& \delta \text { - dimensionless height of porous layer } \\
& \delta_{\mathrm{o}} \text { - viscosity parameter } \\
& \zeta \text { - angle of rotation of obstacle } \\
& \vartheta \text { - angle of inclination of cavity } \\
& \vartheta_{\varphi} \text { - fin inclination angle } \\
& \vartheta_{\rho} \text { - rhombic angle of inclination } \\
& \kappa-\text { thermal conductivity } \\
& \lambda_{w} \text { - wavy surface wavelength } \\
& \lambda \text { - dimensionless distance between heaters (semi-circular) } \\
& \mu-\text { viscosity } \\
& \xi-\text { porosity } \\
& \xi_{\rho} \text { - porosity ratio } \\
& \rho \text { - density } \\
& \sigma-\text { electrical conductivity } \\
& \tau-\text { dimensionless time } \\
& - \text { electric field potential } \\
& \varphi-\text { volume fraction }
\end{aligned}
$$


$\varphi$ - volume concentration

$\Psi$ - phase deviation

\section{Subscript}

ave - average

bf - base fluid

hnf - hybrid nanofluid

loc - local

$n f$ - nanofluid

$n p$ - nanoparticle

\section{References}

[1] S.U.S. Choi, J.A. Eastman, Enhancing thermal conductivity of fluids with nanoparticles, ASME Int. Mech. Eng. Congr. Expo. 66 (1995) 99-105. doi:10.1115/1.1532008.

[2] S.M. Vanaki, P. Ganesan, H.A. Mohammed, Numerical study of convective heat transfer of nanofluids: A review, Renew. Sustain. Energy Rev. 54 (2016) 1212-1239. doi:10.1016/j.rser.2015.10.042.

[3] R.B. Ganvir, P.V. Walke, V.M. Kriplani, Heat transfer characteristics in nanofluid-A review, Renew. Sustain. Energy Rev. 75 (2016) 451-460. doi:10.1016/j.rser.2016.11.010.

[4] L. Syam Sundar, M.K. Singh, Convective heat transfer and friction factor correlations of nanofluid in a tube and with inserts: A review, Renew. Sustain. Energy Rev. 20 (2013) 23-35. doi:10.1016/j.rser.2012.11.041.

[5] P. Keblinski, R. Prasher, J. Eapen, Thermal conductance of nanofluids: Is the controversy over?, J. Nanoparticle Res. 10 (2008) 1089-1097. doi:10.1007/s11051-007-9352-1.

[6] Y. Xuan, Q. Li, Heat transfer enhancement of nanofluids, Int. J. Heat Fluid Flow. 21 (2000) 58-64. doi:10.1016/S0142-727X(99)00067-3.

[7] H.W. Chiam, W.H. Azmi, N.M. Adam, M.K.A.M. Ari, Numerical study of nano fl uid heat transfer for di ff erent tube geometries - A comprehensive review on performance, Int. Commun. Heat Mass Transf. 86 (2017) 60-70. doi:10.1016/j.icheatmasstransfer.2017.05.019.

[8] J. Buongiorno, Convective Transport in Nanofluids, J. Heat Transfer. 128 (2006) $240-250$. doi:10.1115/1.2150834.

[9] H. Masuda, A. Ebata, K. Teramae, N. Hishinuma, Alteration of Thermal Conductivity and Viscosity of Liquid by Dispersing Ultra-Fine Particles., Netsu Bussei. 7 (1993) 227-233. doi:10.2963/jjtp.7.227.

[10] J.A. Eastman, S.U.S. Choi, S. Li, W. Yu, L.J. Thompson, Anomalously increased effective thermal conductivities of ethylene glycol-based nanofluids containing copper nanoparticles, Appl. Phys. Lett. 78 (2001) 718-720. doi:10.1063/1.1341218.

[11] M.M. Tawfik, Experimental studies of nanofluid thermal conductivity enhancement and applications : A review, Renew. Sustain. Energy Rev. 75 (2017) 1239-1253. doi:10.1016/j.rser.2016.11.111.

[12] S. Lee, S.U.-S. Choi, S. Li, J.A. Eastman, Measuring Thermal Conductivity of Fluids Containing Oxide Nanoparticles, J. Heat Transfer. 121 (1999) 280. doi:10.1115/1.2825978.

[13] B.C. Pak, Y.I. Cho, Hydrodynamic and heat transfer study of dispersed fluids with submicron metallic oxide particles, Exp. Heat Transf. 11 (1998) 151-170. doi:10.1080/08916159808946559. 
[14] P. Ternik, Conduction and convection heat transfer characteristics of water-Au nanofluid in a cubic enclosure with differentially heated side walls, Int. J. Heat Mass Transf. 80 (2015) 368-375. doi:10.1016/j.ijheatmasstransfer.2014.09.041.

[15] M. Ahmed, M. Eslamian, Natural convection in a differentially-heated square enclosure filled with a nanofluid: Significance of the thermophoresis force and slip/drift velocity, Int. Commun. Heat Mass Transf. 58 (2014) 1-11. doi:10.1016/j.icheatmasstransfer.2014.08.008.

[16] S. Yekani Motlagh, S. Taghizadeh, H. Soltanipour, Natural convection heat transfer in an inclined square enclosure filled with a porous medium saturated by nanofluid using Buongiorno's mathematical model, Adv. Powder Technol. 27 (2016) 2526-2540. doi:10.1016/j.apt.2016.09.016.

[17] I.D. Garbadeen, M. Sharifpur, J.M. Slabber, J.P. Meyer, Experimental study on natural convection of MWCNT-water nanofluids in a square enclosure, Int. Commun. Heat Mass Transf. 88 (2017) 1-8. doi:10.1016/j.icheatmasstransfer.2017.07.019.

[18] S.Y. Motlagh, H. Soltanipour, Natural convection of Al2O3-water nanofluid in an inclined cavity using Buongiorno's two-phase model, Int. J. Therm. Sci. 111 (2017) 310-320. doi:10.1016/j.ijthermalsci.2016.08.022.

[19] F. Selimefendigil, H.F. Öztop, K. Al-Salem, Natural convection of ferrofluids in partially heated square enclosures, J. Magn. Magn. Mater. 372 (2014) 122-133. doi:10.1016/j.jmmm.2014.07.058.

[20] E. Sourtiji, D.D. Ganji, M. Gorji-Bandpy, S.M. Seyyedi, Numerical study of periodic natural convection in a nanofluid-filled enclosure due to transitional temperature of heat source, Powder Technol. 259 (2014) 65-73. doi:10.1016/j.powtec.2014.03.055.

[21] M. Mahmoodi, S.M. Hashemi, Numerical study of natural convection of a nanofluid in C-shaped enclosures, Int. J. Therm. Sci. 55 (2012) 76-89. doi:10.1016/j.ijthermalsci.2012.01.002.

[22] M. Mahmoodi, Numerical simulation of free convection of a nanofluid in L-shaped cavities, Int. J. Therm. Sci. 50 (2011) 1731-1740. doi:10.1016/j.ijthermalsci.2011.04.009.

[23] M.M. Rahman, S. Saha, S. Mojumder, S. Mekhilef, R. Saidur, Numerical Simulation of Unsteady Heat Transfer in a Half-Moon Shape Enclosure with Variable Thermal Boundary Condition for Different Nanofluids, Numer. Heat Transf. Part B Fundam. 65 (2014) 282-301. doi:10.1080/10407790.2013.849990.

[24] S. Parvin, M.A. Alim, N.F. Hossain, Prandtl number effect on cooling performance of a heated cylinder in an enclosure filled with nanofluid, Int. Commun. Heat Mass Transf. 39 (2012) 1220-1225. doi:10.1016/j.icheatmasstransfer.2012.06.006.

[25] R. Nasrin, S. Parvin, Investigation of buoyancy-driven flow and heat transfer in a trapezoidal cavity filled with water-Cu nanofluid, Int. Commun. Heat Mass Transf. 39 (2012) 270-274. doi:10.1016/j.icheatmasstransfer.2011.11.004.

[26] K. Khanafer, K. Vafai, M. Lightstone, Buoyancy-driven heat transfer enhancement in a twodimensional enclosure utilizing nanofluids, Int. J. Heat Mass Transf. 46 (2003) 3639-3653. doi:10.1016/S00179310(03)00156-X.

[27] A. Brusly Solomon, J. van Rooyen, M. Rencken, M. Sharifpur, J.P. Meyer, Experimental study on the influence of the aspect ratio of square cavity on natural convection heat transfer with Al2O3/Water nanofluids, Int. Commun. Heat Mass Transf. 88 (2017) 254-261. doi:10.1016/j.icheatmasstransfer.2017.09.007.

[28] M. Bouhalleb, H. Abbassi, Numerical Investigation of Heat Transfer by CuO-Water Nanofluid in Rectangular Enclosures, Heat Transf. Eng. 37 (2016) 13-23. doi:10.1080/01457632.2015.1025003.

[29] C.C. Cho, H.T. Yau, C.H. Chiu, K.C. Chiu, Numerical investigation into natural convection and entropy generation in a nanofluid-filled U-shaped cavity, Entropy. 17 (2015) 5980-5994. doi:10.3390/e17095980. 
[30] H.M. Elshehabey, F.M. Hady, S.E. Ahmed, R.A. Mohamed, Numerical investigation for natural convection of a nanofluid in an inclined L-shaped cavity in the presence of an inclined magnetic field, Int. Commun. Heat Mass Transf. 57 (2014) 228-238. doi:10.1016/j.icheatmasstransfer.2014.07.004.

[31] R. Mohebbi, M.M. Rashidi, Numerical simulation of natural convection heat transfer of a nanofluid in an L-shaped enclosure with a heating obstacle, J. Taiwan Inst. Chem. Eng. 72 (2017) 70-84. doi:10.1016/j.jtice.2017.01.006.

[32] N.S. Bondareva, M.A. Sheremet, H.F. Oztop, N. Abu-Hamdeh, Entropy generation due to natural convection of a nanofluid in a partially open triangular cavity, Adv. Powder Technol. 28 (2016) 244-255. doi:10.1016/j.apt.2016.09.030.

[33] Q. Sun, I. Pop, Free convection in a triangle cavity filled with a porous medium saturated with nanofluids with flush mounted heater on the wall, Int. J. Therm. Sci. 50 (2011) 2141-2153. doi:10.1016/j.ijthermalsci.2011.06.005.

[34] M. Jafari, M. Farhadi, S. Akbarzade, M. Ebrahimi, Lattice Boltzmann simulation of natural convection heat transfer of SWCNT-nanofluid in an open enclosure, Ain Shams Eng. J. 6 (2015) 913-927. doi:10.1016/j.asej.2014.12.012.

[35] H. Moradi, B. Bazooyar, S.G. Etemad, A. Moheb, Influence of the geometry of cylindrical enclosure on natural convection heat transfer of Newtonian nanofluids, Chem. Eng. Res. Des. 94 (2015) 673-680. doi:10.1016/j.cherd.2014.10.008.

[36] J. Ravnik, L. Škerget, A numerical study of nanofluid natural convection in a cubic enclosure with a circular and an ellipsoidal cylinder, Int. J. Heat Mass Transf. 89 (2015) 596-605. doi:10.1016/j.ijheatmasstransfer.2015.05.089.

[37] S. Soleimani, M. Sheikholeslami, D.D. Ganji, M. Gorji-Bandpay, Natural convection heat transfer in a nanofluid filled semi-annulus enclosure, Int. Commun. Heat Mass Transf. 39 (2012) 565-574. doi:10.1016/j.icheatmasstransfer.2012.01.016.

[38] M. Sheikholeslami, M. Gorji-Bandpy, G. Domairry, Free convection of nanofluid filled enclosure using lattice Boltzmann method (LBM), Appl. Math. Mech. (English Ed. 34 (2013) 833-846. doi:10.1007/s10483013-1711-9.

[39] R. Anandalakshmi, T. Basak, Heat flow visualization for natural convection in rhombic enclosures due to isothermal and non-isothermal heating at the bottom wall, Int. J. Heat Mass Transf. 55 (2012) 1325-1342. doi:10.1016/j.ijheatmasstransfer.2011.09.006.

[40] O. Haddad, A. Baïri, N. Alilat, J.G. Bauzin, N. Laraqi, Free convection in ZnO-Water nanofluid-filled and tilted hemispherical enclosures containing a cubic electronic device, Int. Commun. Heat Mass Transf. 87 (2017) 204-211. doi:10.1016/j.icheatmasstransfer.2017.06.011.

[41] M. Ghalambaz, M.A. Sheremet, I. Pop, Free Convection in a Parallelogrammic Porous Cavity Filled with a Nanofluid Using Tiwari and Das' Nanofluid Model, (n.d.). doi:10.1371/journal.pone.0126486.

[42] M.A. Mansour, A.Y. Bakier, M.A.Y. Bakier, Natural convection of the localized heat sources of T-shaped nanofluid-filled enclosures, (2013) 49-61.

[43] R. Dehnavi, A. Rezvani, Numerical investigation of natural convection heat transfer of nanofluids in a ? shaped cavity, Superlattices Microstruct. 52 (2012) 312-325. doi:10.1016/j.spmi.2012.05.006.

[44] S. Dong, B. Cao, Z. Guo, Numerical investigation of nanofluid flow and heat transfer around a calabashshaped body, Numer. Heat Transf. Part A Appl. 68 (2015) 548-565. doi:10.1080/10407782.2014.986397.

[45] O. Zeitoun, Numerical modeling of natural convection heat transfer from a horizontal torus, Numer. Heat Transf. Part A Appl. 65 (2014) 911-930. doi:10.1080/10407782.2013.875796. 
[46] A. Al-Zamily, M.R. Amin, Natural Convection and Entropy Generation in a NanofluidFilled Semi-Circular Enclosure with Heat Flux Source, Procedia Eng. 105 (2015) 418-424. doi:10.1016/j.proeng.2015.05.028.

[47] W. Tang, M. Hatami, J. Zhou, D. Jing, Natural convection heat transfer in a nanofluid-filled cavity with double sinusoidal wavy walls of various phase deviations, Int. J. Heat Mass Transf. 115 (2017) 430-440. doi:10.1016/j.ijheatmasstransfer.2017.07.057.

[48] H. Bararnia, K. Hooman, D.D. Ganji, NATURAL CONVECTION IN A NANOFLUIDS-FILLED PORTIONED CAVITY: THE LATTICE-BOLTZMANN METHOD, Numer. Heat Transf. Part a-Applications. 59 (2011) 487-502. doi:10.1080/10407782.2011.541195.

[49] S. Parvin, R. Nasrin, M.A. Alim, Heat transfer performance of nanofluid in a complicated cavity due to Prandtl number variation, in: Procedia Eng., 2014: pp. 377-382. doi:10.1016/j.proeng.2014.11.865.

[50] S. Parvin, A.J. Chamkha, An analysis on free convection flow, heat transfer and entropy generation in an odd-shaped cavity filled with nanofluid, Int. Commun. Heat Mass Transf. 54 (2014) 8-17. doi:10.1016/j.icheatmasstransfer.2014.02.031.

[51] D. Das, M. Roy, T. Basak, Studies on natural convection within enclosures of various (non-square) shapes - A review, Int. J. Heat Mass Transf. 106 (2016) 356-406. doi:10.1016/j.ijheatmasstransfer.2016.08.034.

[52] K. Kalidasan, P. Rajesh Kanna, Natural convection on an open square cavity containing diagonally placed heaters and adiabatic square block and filled with hybrid nanofluid of nanodiamond - cobalt oxide/water, Int. Commun. Heat Mass Transf. 81 (2017) 64-71. doi:10.1016/j.icheatmasstransfer.2016.12.005.

[53] A. Brusly Solomon, M. Sharifpur, T. Ottermann, C. Grobler, M. Joubert, J.P. Meyer, Natural convection enhancement in a porous cavity with Al2O3-Ethylene glycol/water nanofluids, Int. J. Heat Mass Transf. 108 (2017) 1324-1334. doi:10.1016/j.ijheatmasstransfer.2017.01.009.

[54] M. Sheikholeslami, M. Seyednezhad, Lattice Boltzmann method simulation for CuO-water nanofluid flow in a porous enclosure with hot obstacle, J. Mol. Liq. 243 (2017) 249-256. doi:10.1016/j.molliq.2017.08.038.

[55] K.S. Suganthi, K.S. Rajan, Metal oxide nanofluids: Review of formulation, thermo-physical properties, mechanisms, and heat transfer performance, Renew. Sustain. Energy Rev. 76 (2017) 226-255. doi:10.1016/j.rser.2017.03.043.

[56] I. V. Miroshnichenko, M.A. Sheremet, I. Pop, Natural convection in a trapezoidal cavity filled with a micropolar fluid under the effect of a local heat source, Int. J. Mech. Sci. 120 (2017) 182-189. doi:10.1016/j.ijmecsci.2016.11.028.

[57] N.S. Gibanov, M.A. Sheremet, I. Pop, Natural convection of micropolar fluid in a wavy differentially heated cavity, J. Mol. Liq. 221 (2016) 518-525. doi:10.1016/j.molliq.2016.06.033.

[58] M. Muthtamilselvan, K. Periyadurai, D.H. Doh, Effect of uniform and nonuniform heat source on natural convection flow of micropolar fluid, Int. J. Heat Mass Transf. 115 (2017) 19-34. doi:10.1016/j.ijheatmasstransfer.2017.06.134.

[59] G.C. Bourantas, V.C. Loukopoulos, Modeling the natural convective flow of micropolar nanofluids, Int. J. Heat Mass Transf. 68 (2014) 35-41. doi:10.1016/j.ijheatmasstransfer.2013.09.006.

[60] H. Hashemi, Z. Namazian, S.A.M. Mehryan, Cu-water micropolar nanofluid natural convection within a porous enclosure with heat generation, J. Mol. Liq. 236 (2017) 48-60. doi:10.1016/j.molliq.2017.04.001.

[61] A.A. Minea, W.M. El-Maghlany, Natural convection heat transfer utilizing ionic nanofluids with temperature-dependent thermophysical properties, Chem. Eng. Sci. 174 (2017) 13-24. doi:10.1016/j.ces.2017.08.028. 
[62] M. Izadi, R. Mohebbi, D. Karimi, M.A. Sheremet, Numerical simulation of natural convection heat transfer inside a + shaped cavity filled by a MWCNT-Fe 3 O 4 /water hybrid nanofluids using LBM, Chem. Eng. Process. - Process Intensif. 125 (2018) 56-66. doi:10.1016/j.cep.2018.01.004.

[63] A.B. Solomon, M. Sharifpur, J.P. Meyer, J.S. Ibrahim, B. Immanuel, Convection heat transfer with water based mango bark nanofluids, in: 13th Int. Conf. Heat Transf. Fluid Mech. Thermodyn., Portorož, Slovenia, 2017.

[64] A. V. Kuznetsov, The onset of nanofluid bioconvection in a suspension containing both nanoparticles and gyrotactic microorganisms, Int. Commun. Heat Mass Transf. 37 (2010) 1421-1425. doi:10.1016/j.icheatmasstransfer.2010.08.015.

[65] M.A. Sheremet, I. Pop, Thermo-Bioconvection in a Square Porous Cavity Filled by Oxytactic Microorganisms, Transp. Porous Media. 103 (2014) 191-205. doi:10.1007/s11242-014-0297-4.

[66] T. Nguyen-Quang, Onset of gravitactic bioconvection in a square anisotropic porous medium with arbitrary orientation of the principal axes, Int. J. Heat Mass Transf. 51 (2008) 1497-1504. doi:10.1016/j.ijheatmasstransfer.2007.07.035.

[67] M. Sheikholeslami, A.J. Chamkha, Electrohydrodynamic free convection heat transfer of a nanofluid in a semi-annulus enclosure with a sinusoidal wall, Numer. Heat Transf. Part A Appl. 69 (2016) 781-793. doi:10.1080/10407782.2015.1090819.

[68] M. Sheikholeslami, M.M. Bhatti, Active method for nanofluid heat transfer enhancement by means of EHD, Int. J. Heat Mass Transf. 109 (2017) 115-122. doi:10.1016/j.ijheatmasstransfer.2017.01.115.

[69] U. Khan, N. Ahmed, S.T. Mohyud-Din, B. Bin-Mohsin, A bioconvection model for MHD flow and heat transfer over a porous wedge containing both nanoparticles and gyrotatic microorganisms, J. Biol. Syst. 24 (2016) 409-429. doi:10.1142/S0218339016500212.

[70] U. Khan, N. Ahmed, S.T. Mohyud-Din, Influence of viscous dissipation and Joule heating on MHD bio-convection flow over a porous wedge in the presence of nanoparticles and gyrotactic microorganisms, Springerplus. 5 (2016) 2043. doi:10.1186/s40064-016-3718-8.

[71] N. Makulati, A. Kasaeipoor, M.M. Rashidi, Numerical study of natural convection of a water-alumina nanofluid in inclined C-shaped enclosures under the effect of magnetic field, Adv. Powder Technol. 27 (2016) 661-672. doi:10.1016/j.apt.2016.02.020.

[72] B. Ghasemi, Magnetohydrodynamic Natural Convection of Nanofluids in U-shaped Enclosures, Numer. Heat Transf. Part A Appl. 63 (2013) 473-487. doi:10.1080/10407782.2013.742728.

[73] S. Mojumder, K.M. Rabbi, S. Saha, M.N. Hasan, S.C. Saha, Magnetic field effect on natural convection and entropy generation in a half-moon shaped cavity with semi-circular bottom heater having different ferrofluid inside, J. Magn. Magn. Mater. 407 (2016) 412-424. doi:10.1016/j.jmmm.2016.01.046.

[74] F. Selimefendigil, H.F. Öztop, Conjugate natural convection in a nanofluid filled partitioned horizontal annulus formed by two isothermal cylinder surfaces under magnetic field, Int. J. Heat Mass Transf. 108 (2017) 156-171. doi:10.1016/j.ijheatmasstransfer.2016.11.080.

[75] L. Wang, Z. Chai, B. Shi, Lattice Boltzmann Simulation of Magnetic Field Effect on Natural Convection of Power-Law Nanofluids in Rectangular Enclosures, Adv. Appl. Math. Mech. 9 (2017) 1094-1110. doi:10.4208/aamm.OA-2016-0066.

[76] M. Sheikholeslami, D.D. Ganji, Ferrofluid convective heat transfer under the influence of external magnetic source, Alexandria Eng. J. (2016) 0-11. doi:10.1016/j.aej.2016.11.007.

[77] M. Sheikholeslami, M. Gorji-Bandpy, D.D. Ganji, S. Soleimani, Natural convection heat transfer in a cavity with sinusoidal wall filled with $\mathrm{CuO}$-water nanofluid in presence of magnetic field, J. Taiwan Inst. Chem. Eng. 45 (2014) 40-49. doi:10.1016/j.jtice.2013.04.019. 
[78] A. Shahriari, H.R. Ashorynejad, I. Pop, Entropy generation of MHD nanofluid inside an inclined wavy cavity by lattice Boltzmann method, J. Therm. Anal. Calorim. 3456789 (2018) 1-21. doi:10.1007/s10973018-7061-x.

[79] A.R. Rahmati, M. Sepehrnia, M. Motamedian, Numerical simulation of turbulent natural convection of nanofluid with thermal radiation inside a tall enclosure under the influence of magnetohydrodynamic, Heat Transf. - Asian Res. 48 (2019) 520-538. doi:10.1002/htj.21382.

[80] A.M. Rashad, M.M. Rashidi, G. Lorenzini, S.E. Ahmed, A.M. Aly, Magnetic field and internal heat generation effects on the free convection in a rectangular cavity filled with a porous medium saturated with $\mathrm{Cu}_{-}^{-}$ water nanofluid, Int. J. Heat Mass Transf. 104 (2017) 878-889. doi:10.1016/j.ijheatmasstransfer.2016.08.025.

[81] M. Sheikholeslami, T. Hayat, A. Alsaedi, Numerical study for external magnetic source influence on water based nanofluid convective heat transfer, Int. J. Heat Mass Transf. 106 (2017) 745-755. doi:10.1016/j.ijheatmasstransfer.2016.09.077.

[82] A.M.J. Al-Zamily, Effect of magnetic field on natural convection in a nanofluid-filled semi-circular enclosure with heat flux source, Comput. Fluids. 103 (2014) 71-85. doi:10.1016/j.compfluid.2014.07.013.

[83] M. Sheikholeslami, M. Shamlooei, Magnetic source influence on nanofluid flow in porous medium considering shape factor effect, Phys. Lett. A. 381 (2017) 3071-3078. doi:10.1016/j.physleta.2017.07.028.

[84] M. Sheikholeslami, D.D. Ganji, Ferrohydrodynamic and magnetohydrodynamic effects on ferrofluid flow and convective heat transfer, Energy. 75 (2014) 400-410. doi:10.1016/j.energy.2014.07.089.

[85] M. Hatami, J. Zhou, J. Geng, D. Jing, Variable magnetic field (VMF) effect on the heat transfer of a half-annulus cavity filled by Fe3O4-water nanofluid under constant heat flux, J. Magn. Magn. Mater. 451 (2018) 173-182. doi:10.1016/j.jmmm.2017.10.110.

[86] M. Sheikholeslami, H.B. Rokni, Numerical modeling of nanofluid natural convection in a semi annulus in existence of Lorentz force, Comput. Methods Appl. Mech. Eng. 317 (2017). doi:10.1016/j.cma.2016.12.028.

[87] M. Sheikholeslami, M. Gorji-Bandpay, D.D. Ganji, Magnetic field effects on natural convection around a horizontal circular cylinder inside a square enclosure filled with nanofluid, Int. Commun. Heat Mass Transf. 39 (2012) 978-986. doi:10.1016/j.icheatmasstransfer.2012.05.020.

[88] M. Sheikholeslami, M. Gorji-Bandpy, K. Vajravelu, Lattice Boltzmann simulation of magnetohydrodynamic natural convection heat transfer of $\mathrm{Al} 2 \mathrm{O} 3$-water nanofluid in a horizontal cylindrical enclosure with an inner triangular cylinder, Int. J. Heat Mass Transf. 80 (2015) 16-25. doi:10.1016/j.ijheatmasstransfer.2014.08.090.

[89] M. Sheikholeslami, Z. Ziabakhsh, D.D. Ganji, Transport of Magnetohydrodynamic nanofluid in a porous media, Colloids Surfaces A Physicochem. Eng. Asp. 520 (2017) 201-212. doi:10.1016/j.colsurfa.2017.01.066.

[90] M. Sheikholeslami, T. Hayat, A. Alsaedi, On simulation of nanofluid radiation and natural convection in an enclosure with elliptical cylinders, Int. J. Heat Mass Transf. 115 (2017) 981-991. doi:10.1016/j.ijheatmasstransfer.2017.07.119.

[91] A.S. Dogonchi, M. Waqas, S.M. Seyyedi, M. Hashemi-Tilehnoee, D.D. Ganji, CVFEM analysis for Fe3O4-H2O nanofluid in an annulus subject to thermal radiation, Int. J. Heat Mass Transf. 132 (2019) 473-483. doi:10.1016/j.ijheatmasstransfer.2018.11.124.

[92] M. Sheikholeslami, H.F. Oztop, MHD free convection of nanofluid in a cavity with sinusoidal walls by using CVFEM, Chinese J. Phys. 55 (2017) 2291-2304. doi:10.1016/j.cjph.2017.09.006.

[93] A.S. Dogonchi, Hashim, Heat transfer by natural convection of Fe3O4-water nanofluid in an annulus between a wavy circular cylinder and a rhombus, Int. J. Heat Mass Transf. 130 (2019) 320-332. doi:10.1016/j.ijheatmasstransfer.2018.10.086. 
[94] Z. Li, M. Sheikholeslami, A.J. Chamkha, Z.A. Raizah, S. Saleem, Control volume finite element method for nanofluid MHD natural convective flow inside a sinusoidal annulus under the impact of thermal radiation, Comput. Methods Appl. Mech. Eng. 338 (2018) 618-633. doi:10.1016/j.cma.2018.04.023.

[95] M.R. Hajmohammadi, M.H. Haji Molla Ali Tork, Effects of the magnetic field on the cylindrical Couette flow and heat transfer of a nanofluid, Phys. A Stat. Mech. Its Appl. 523 (2019) 234-245. doi:10.1016/j.physa.2019.02.037.

[96] F.S. Oğlakkaya, C. Bozkaya, MHD natural convection in a semi-annulus enclosure filled with water-based nanofluid using DRBEM, Eng. Anal. Bound. Elem. 71 (2016) 151-163. doi:10.1016/j.enganabound.2016.07.013.

[97] M. Tezer-sezgin, C. Bozkaya, Ö. Türk, Natural convection flow of a nanofluid in an enclosure under an inclined uniform magnetic field, Eur. J. Comput. Mech. 7179 (2017) 1-22. doi:10.1080/17797179.2016.1181029.

[98] M. Sheikholeslami, M. Gorji-Bandpy, D.D. Ganji, S. Soleimani, Effect of a magnetic field on natural convection in an inclined half-annulus enclosure filled with $\mathrm{Cu}$-water nanofluid using CVFEM, Adv. Powder Technol. 24 (2013) 980-991. doi:10.1016/j.apt.2013.01.012.

[99] M. Sheikholeslami, D.D. Ganji, M.M. Rashidi, Ferrofluid flow and heat transfer in a semi annulus enclosure in the presence of magnetic source considering thermal radiation, J. Taiwan Inst. Chem. Eng. 47 (2015) 6-17. doi:10.1016/j.jtice.2014.09.026.

[100] M. Sheikholeslami, D.D. Ganji, R. Moradi, Heat transfer of Fe3O4-water nanofluid in a permeable medium with thermal radiation in existence of constant heat flux, Chem. Eng. Sci. 174 (2017) 326-336. doi:10.1016/j.ces.2017.09.026.

[101] M. Sheikholeslami, H.B. Rokni, Nanofluid convective heat transfer intensification in a porous circular cylinder, Chem. Eng. Process. Process Intensif. 120 (2017) 93-104. doi:10.1016/j.cep.2017.07.001.

[102] M. Sheikholeslami, D.D. Ganji, Transportation of MHD nanofluid free convection in a porous semi annulus using numerical approach, Chem. Phys. Lett. 669 (2017) 202-210. doi:http://dx.doi.org/10.1016/j.cplett.2016.12.045.

[103] M. Sheikholeslami, S.A. Shehzad, Magnetohydrodynamic nanofluid convection in a porous enclosure considering heat flux boundary condition, Int. J. Heat Mass Transf. 106 (2017) 1261-1269. doi:10.1016/j.ijheatmasstransfer.2016.10.107.

[104] M. Sheikholeslami, M. Seyednezhad, Nanofluid heat transfer in a permeable enclosure in presence of variable magnetic field by means of CVFEM, Int. J. Heat Mass Transf. 114 (2017) 1169-1180. doi:10.1016/j.ijheatmasstransfer.2017.07.018.

[105] M. Sheikholeslami, D.D. Ganji, Numerical analysis of nanofluid transportation in porous media under the influence of external magnetic source, J. Mol. Liq. 233 (2017) 499-507. doi:10.1016/j.molliq.2017.03.050.

[106] M. Sheikholeslami, A. Zeeshan, Analysis of flow and heat transfer in water based nanofluid due to magnetic field in a porous enclosure with constant heat flux using CVFEM, Comput. Methods Appl. Mech. Eng. 320 (2017) 68-81. doi:10.1016/j.cma.2017.03.024.

[107] M. Sheikholeslami, S.A. Shehzad, Simulation of water based nanofluid convective flow inside a porous enclosure via non-equilibrium model, Int. J. Heat Mass Transf. 120 (2018) 1200-1212. doi:10.1016/j.ijheatmasstransfer.2017.12.132.

[108] M. Sheikholeslami, H.B. Rokni, CVFEM for effect of Lorentz forces on nanofluid flow in a porous complex shaped enclosure by means of non-equilibrium model, J. Mol. Liq. 254 (2018) 446-462. doi:10.1016/j.molliq.2018.01.130.

[109] M. Sheikholeslami, S.A. Shehzad, Numerical analysis of Fe3O4-H2O nanofluid flow in permeable media under the effect of external magnetic source, Int. J. Heat Mass Transf. 118 (2018) 182-192. 
doi:10.1016/j.ijheatmasstransfer.2017.10.113.

[110] A.S. Dogonchi, M.A. Sheremet, D.D. Ganji, I. Pop, Free convection of copper-water nanofluid in a porous gap between hot rectangular cylinder and cold circular cylinder under the effect of inclined magnetic field, J. Therm. Anal. Calorim. 135 (2019) 1171-1184. doi:10.1007/s10973-018-7396-3.

[111] A.H. Mahmoudi, I. Pop, M. Shahi, Effect of magnetic field on natural convection in a triangular enclosure filled with nanofluid, Int. J. Therm. Sci. 59 (2012) 126-140. doi:10.1016/j.ijthermalsci.2012.04.006.

[112] M.M. Rahman, M.S. Alam, N. Al-Salti, I.A. Eltayeb, Hydromagnetic natural convective heat transfer flow in an isosceles triangular cavity filled with nanofluid using two-component nonhomogeneous model, Int. J. Therm. Sci. 107 (2016) 272-288. doi:10.1016/j.ijthermalsci.2016.04.009.

[113] M.M. Rahman, Influence of oriented magnetic field on natural convection in an equilateral triangular enclosure filled with water- and kerosene-based ferrofluids using a two-component nonhomogeneous thermal equilibrium model, Cogent Phys. 3 (2016) 1-15. doi:10.1080/23311940.2016.1234662.

[114] A.S. Dogonchi, M. Hashemi-Tilehnoee, M. Waqas, S.M. Seyyedi, I.L. Animasaun, D.D. Ganji, The influence of different shapes of nanoparticle on $\mathrm{Cu}-\mathrm{H} 2 \mathrm{O}$ nanofluids in a partially heated irregular wavy enclosure, Phys. A Stat. Mech. Its Appl. 540 (2020) 123034. doi:10.1016/j.physa.2019.123034.

[115] A.S. Dogonchi, M.A. Ismael, A.J. Chamkha, D.D. Ganji, Numerical analysis of natural convection of $\mathrm{Cu}$-water nanofluid filling triangular cavity with semicircular bottom wall, J. Therm. Anal. Calorim. 135 (2019) 3485-3497. doi:10.1007/s10973-018-7520-4.

[116] S.E. Ahmed, Z.Z. Rashed, MHD natural convection in a heat generating porous medium-filled wavy enclosures using Buongiorno's nanofluid model, Case Stud. Therm. Eng. 14 (2019) 100430. doi:10.1016/j.csite.2019.100430.

[117] Y. Ma, R. Mohebbi, M.M. Rashidi, Z. Yang, M.A. Sheremet, Numerical study of MHD nanofluid natural convection in a baffled U-shaped enclosure, Int. J. Heat Mass Transf. 130 (2019) 123-134. doi:10.1016/j.ijheatmasstransfer.2018.10.072.

[118] Y. Ma, R. Mohebbi, M.M. Rashidi, O. Manca, Z. Yang, Numerical investigation of MHD effects on nanofluid heat transfer in a baffled U-shaped enclosure using lattice Boltzmann method, J. Therm. Anal. Calorim. 135 (2019) 3197-3213. doi:10.1007/s10973-018-7518-y.

[119] A.K. Hussein, M.A.Y. Bakier, M.B. Ben Hamida, S. Sivasankaran, Magneto-hydrodynamic natural convection in an inclined T-shaped enclosure for different nanofluids and subjected to a uniform heat source, Alexandria Eng. J. 55 (2016) 2157-2169. doi:10.1016/j.aej.2016.06.020.

[120] B. Mliki, M.A. Abbassi, A. Omri, Z. Belkacem, Lattice Boltzmann analysis of MHD natural convection of $\mathrm{CuO}$-water nanofluid in inclined $\mathrm{C}$-shaped enclosures under the effect of nanoparticles Brownian motion, Powder Technol. 308 (2017) 70-83. doi:10.1016/j.powtec.2016.11.054.

[121] N. Rahimpour, M. Keshavarz Moraveji, Free convection of water-Fe3O4nanofluid in an inclined cavity subjected to a magnetic field: CFD modeling, sensitivity analysis, Adv. Powder Technol. 28 (2017) 1573-1584. doi:10.1016/j.apt.2017.03.029.

[122] A. Abedini, T. Armaghani, A.J. Chamkha, MHD free convection heat transfer of a water-Fe 3 O 4 nanofluid in a baffled C-shaped enclosure, J. Therm. Anal. Calorim. 135 (2019) 685-695. doi:10.1007/s10973018-7225-8.

[123] A.H. Mahmoudi, I. Pop, M. Shahi, F. Talebi, MHD natural convection and entropy generation in a trapezoidal enclosure using $\mathrm{Cu}$-water nanofluid, Comput. Fluids. 72 (2013) 46-62. doi:10.1016/j.compfluid.2012.11.014.

[124] V.M. Job, S.R. Gunakala, Unsteady MHD free convection nanofluid flows within a wavy trapezoidal enclosure with viscous and Joule dissipation effects, Numer. Heat Transf. Part A Appl. 69 (2016) 421-443. 
doi:10.1080/10407782.2015.1080946.

[125] V.M. Job, S.R. Gunakala, B. Rushi Kumar, R. Sivaraj, Time-dependent hydromagnetic free convection nanofluid flows within a wavy trapezoidal enclosure, Appl. Therm. Eng. 115 (2017) 363-377. doi:10.1016/j.applthermaleng.2016.12.084.

[126] I. V. Miroshnichenko, M.A. Sheremet, H.F. Oztop, K. Al-Salem, MHD natural convection in a partially open trapezoidal cavity filled with a nanofluid, Int. J. Mech. Sci. 119 (2016) 294-302. doi:10.1016/j.ijmecsci.2016.11.001.

[127] P.I. Bondareva, N.S., Sheremet, M.A., Magnetic field effect on the unsteady natural convection in a right-angle trapezoidal cavity filled with a nanofluid, Int. J. Numer. Methods Heat Fluid Flow. 25 (2015).

[128] M.S. Astanina, M.A. Sheremet, H.F. Oztop, N. Abu-Hamdeh, MHD natural convection and entropy generation of ferrofluid in an open trapezoidal cavity partially filled with a porous medium, Int. J. Mech. Sci. 136 (2018) 493-502. doi:10.1016/j.ijmecsci.2018.01.001.

[129] I. Mejri, A. Mahmoudi, MHD natural convection in a nanofluid-filled open enclosure with a sinusoidal boundary condition, Chem. Eng. Res. Des. 98 (2015) 1-16. doi:10.1016/j.cherd.2015.03.028.

[130] G.R. Kefayati, Effect of a magnetic field on natural convection in an open cavity subjugated to water/alumina nanofluid using Lattice Boltzmann method, Int. Commun. Heat Mass Transf. 40 (2013) 67-77. doi:10.1016/j.icheatmasstransfer.2012.10.024.

[131] A.K. Hussein, H.R. Ashorynejad, M. Shikholeslami, S. Sivasankaran, Lattice Boltzmann simulation of natural convection heat transfer in an open enclosure filled with $\mathrm{Cu}$-water nanofluid in a presence of magnetic field, Nucl. Eng. Des. 268 (2014) 10-17. doi:10.1016/j.nucengdes.2013.11.072.

[132] M.A. Sheremet, H.F. Oztop, I. Pop, K. Al-Salem, MHD free convection in a wavy open porous tall cavity filled with nanofluids under an effect of corner heater, Int. J. Heat Mass Transf. 103 (2016) 955-964. doi:10.1016/j.ijheatmasstransfer.2016.08.006.

[133] N.S. Bondareva, M.A. Sheremet, H.F. Oztop, N. Abu-Hamdeh, Heatline visualization of MHD natural convection in an inclined wavy open porous cavity filled with a nanofluid with a local heater, Int. J. Heat Mass Transf. 99 (2016) 872-881. doi:10.1016/j.ijheatmasstransfer.2016.04.055.

[134] M. Sheikholeslami, Influence of magnetic field on nanofluid free convection in an open porous cavity by means of Lattice Boltzmann method, J. Mol. Liq. 234 (2017) 364-374. doi:10.1016/j.molliq.2017.03.104.

[135] L. Kolsi, A.A.A.A. Alrashed, K. Al-Salem, H.F. Oztop, M.N. Borjini, Control of natural convection via inclined plate of CNT-water nanofluid in an open sided cubical enclosure under magnetic field, Int. J. Heat Mass Transf. 111 (2017) 1007-1018. doi:10.1016/j.ijheatmasstransfer.2017.04.069.

[136] M. Sheikholeslami, H.B. Rokni, Free convection of $\mathrm{CuO}-\mathrm{H} 2 \mathrm{O}$ nanofluid in a curved porous enclosure using mesoscopic approach, Int. J. Hydrogen Energy. 42 (2017) 14942-14949. doi:10.1016/j.ijhydene.2017.04.217.

[137] M. Sheikholeslami, M. Shamlooei, Fe3O4-H2O nanofluid natural convection in presence of thermal radiation, Int. J. Hydrogen Energy. (2017). doi:10.1016/j.ijhydene.2017.02.031.

[138] M. Sheikholeslami, D.D. Ganji, Numerical investigation of nanofluid transportation in a curved cavity in existence of magnetic source, Chem. Phys. Lett. 667 (2017) 307-316. doi:10.1016/j.cplett.2016.11.013.

[139] M. Sheikholeslami, D.D. Ganji, Free convection of Fe3O4-water nanofluid under the influence of an external magnetic source, J. Mol. Liq. 229 (2017) 530-540. doi:10.1016/j.molliq.2016.12.101.

[140] M. Sheikholeslami, Numerical simulation of magnetic nanofluid natural convection in porous media, Phys. Lett. A. 381 (2017) 494-503. doi:10.1016/j.physleta.2016.11.042. 
[141] C.C. Cho, Influence of magnetic field on natural convection and entropy generation in Cuwater nanofluid-filled cavity with wavy surfaces, Int. J. Heat Mass Transf. 101 (2016) 637-647. doi:10.1016/j.ijheatmasstransfer.2016.05.044.

[142] M. Sheikholeslami, M. Gorji-Bandpy, D.D. Ganji, S. Soleimani, S.M. Seyyedi, Natural convection of nanofluids in an enclosure between a circular and a sinusoidal cylinder in the presence of magnetic field, Int. Commun. Heat Mass Transf. 39 (2012) 1435-1443. doi:10.1016/j.icheatmasstransfer.2012.07.026.

[143] M. Sheikholeslami, H.B. Rokni, Magnetic nanofluid natural convection in the presence of thermal radiation considering variable viscosity, Eur. Phys. J. Plus. 132 (2017) 238. doi:10.1140/epjp/i2017-11498-4.

[144] M. Sheikholeslami, Magnetic field influence on nanofluid thermal radiation in a cavity with tilted elliptic inner cylinder, J. Mol. Liq. 229 (2017) 137-147. doi:10.1016/j.molliq.2016.12.024.

[145] M. Sheikholeslami, H.B. Rokni, Magnetohydrodynamic CuO-Water Nanofluid in a Porous ComplexShaped Enclosure, J. Therm. Sci. Eng. Appl. 9 (2017) 041007. doi:10.1115/1.4035973.

[146] M. Sheikholeslami, S.A. Shehzad, Non-Darcy free convection of Fe3O4-water nanoliquid in a complex shaped enclosure under impact of uniform Lorentz force, Chinese J. Phys. 56 (2018) 270-281. doi:10.1016/j.cjph.2017.12.017.

[147] A.S. Dogonchi, F. Selimefendigil, D.D. Ganji, Magneto-hydrodynamic natural convection of CuO-water nanofluid in complex shaped enclosure considering various nanoparticle shapes, Int. J. Numer. Methods Heat Fluid Flow. 29 (2019) 1663-1679. doi:10.1108/HFF-06-2018-0294.

[148] D.D. Vo, M. Hedayat, T. Ambreen, S.A. Shehzad, M. Sheikholeslami, A. Shafee, T.K. Nguyen, Effectiveness of various shapes of $\mathrm{Al} 2 \mathrm{O} 3$ nanoparticles on the MHD convective heat transportation in porous medium: CVFEM modelling, J. Therm. Anal. Calorim. 4 (2019). doi:10.1007/s10973-019-08501-4.

[149] A.S. Dogonchi, M. Waqas, S.M. Seyyedi, M. Hashemi-Tilehnoee, D.D. Ganji, Numerical simulation for thermal radiation and porous medium characteristics in flow of CuO-H2O nanofluid, J. Brazilian Soc. Mech. Sci. Eng. 41 (2019) 1-13. doi:10.1007/s40430-019-1752-5.

[150] S. Parvin, A. Akter, Effect of magnetic field on natural convection flow in a prism shaped cavity filled with nanofluid, Procedia Eng. 194 (2017) 421-427. doi:10.1016/j.proeng.2017.08.166.

[151] S. Dutta, N. Goswami, A.K. Biswas, S. Pati, Numerical investigation of magnetohydrodynamic natural convection heat transfer and entropy generation in a rhombic enclosure filled with $\mathrm{Cu}$-water nanofluid, Int. J. Heat Mass Transf. 136 (2019) 777-798. doi:10.1016/j.ijheatmasstransfer.2019.03.024.

[152] L. Benos, I.E. Sarris, Analytical study of the magnetohydrodynamic natural convection of a nanofluid filled horizontal shallow cavity with internal heat generation, Int. J. Heat Mass Transf. 130 (2019) 862-873. doi:10.1016/j.ijheatmasstransfer.2018.11.004.

[153] L.T. Benos, E.G. Karvelas, I.E. Sarris, A theoretical model for the magnetohydrodynamic natural convection of a CNT-water nanofluid incorporating a renovated Hamilton-Crosser model, Int. J. Heat Mass Transf. 135 (2019) 548-560. doi:10.1016/j.ijheatmasstransfer.2019.01.148.

[154] H.R. Ashorynejad, A. Shahriari, MHD natural convection of hybrid nanofluid in an open wavy cavity, Results Phys. 9 (2018) 440-455. doi:10.1016/j.rinp.2018.02.045.

[155] A.M. Rashad, A.J. Chamkha, M.A. Ismael, T. Salah, Magnetohydrodynamics Natural Convection in a Triangular Cavity Filled With a $\mathrm{Cu}-\mathrm{Al}_{2} \mathrm{O}_{3}$ /Water Hybrid Nanofluid With Localized Heating From Below and Internal Heat Generation, J. Heat Transfer. 140 (2018) 072502. doi:10.1115/1.4039213.

[156] S.A.M. Mehryan, M.A. Sheremet, M. Soltani, M. Izadi, Natural convection of magnetic hybrid nanofluid inside a double-porous medium using two-equation energy model, J. Mol. Liq. 277 (2019) 959-970. doi:10.1016/j.molliq.2018.12.147. 
[157] M.K. Abdolbaqi, W.H. Azmi, R. Mamat, K.V. Sharma, G. Najafi, Experimental Investigation of Thermal Conductivity and Electrical Conductivity of BioGlycol - Water Mixture Based Al2O3 Nanofluid, Appl. Therm. Eng. 102 (2016) 932-941. doi:10.1016/j.applthermaleng.2016.03.074.

[158] S.O. Giwa, M. Sharifpur, J.P. Meyer, Experimental study of thermo-convection performance of hybrid nanofluids of Al 2 O 3 -MWCNT / water in a differentially heated square cavity, Int. J. Heat Mass Transf. (2019) 119072. doi:10.1016/j.ijheatmasstransfer.2019.119072.

[159] M.S. Astanina, M. Kamel Riahi, E. Abu-Nada, M.A. Sheremet, Magnetohydrodynamic in partially heated square cavity with variable properties: Discrepancy in experimental and theoretical conductivity correlations, Int. J. Heat Mass Transf. 116 (2018) 532-548. doi:10.1016/j.ijheatmasstransfer.2017.09.050.

[160] M.A. Sheremet, H.F. Oztop, I. Pop, MHD natural convection in an inclined wavy cavity with corner heater filled with a nanofluid, J. Magn. Magn. Mater. 416 (2016) 37-47. doi:10.1016/j.jmmm.2016.04.061.

[161] M. Sheikholeslami, S. Abelman, Two Phase Simulation of Nanofluid Flow and Heat Transfer in an Annulus in the Presence of an Axial Magnetic Field, IEEE Trans. Nanotechnol. 14 (2015) 561-569. doi:10.1109/TNANO.2015.2416318.

[162] M. Sheikholeslami, D.D. Ganji, Ferrofluid convective heat transfer under the influence of external magnetic source, Alexandria Eng. J. 57 (2018) 121-130. doi:10.1016/j.aej.2016.11.007.

[163] S.E. Ahmed, M.A. Mansour, A.M. Rashad, T. Salah, MHD natural convection from two heating modes in fined triangular enclosures filled with porous media using nanofluids, J. Therm. Anal. Calorim. 0123456789 (2019). doi:10.1007/s10973-019-08675-x.

[164] M. Mamourian, K. Milani Shirvan, I. Pop, Sensitivity analysis for MHD effects and inclination angles on natural convection heat transfer and entropy generation of Al2O3-water nanofluid in square cavity by Response Surface Methodology, Int. Commun. Heat Mass Transf. 79 (2016) 46-57. doi:10.1016/j.icheatmasstransfer.2016.10.001.

[165] M. Sheikholeslami, S.A. Shehzad, Magnetohydrodynamic nanofluid convective flow in a porous enclosure by means of LBM, Int. J. Heat Mass Transf. 113 (2017) 796-805. doi:10.1016/j.ijheatmasstransfer.2017.05.130.

[166] A. Mahmoudi, I. Mejri, M. Ammarabbassi, A. Omri, MHD natural convection in a nanofluid-filled cavity with linear temperature distribution, J. Comput. Methods Sci. Eng. 14 (2014) 291-313. doi:10.3233/JCM140503.

[167] A.H. Mahmoudi, E. Abu-Nada, Combined Effect of Magnetic Field and Nanofluid Variable Properties on Heat Transfer Enhancement in Natural Convection, Numer. Heat Transf. Part A Appl. 63 (2013) 452-472. doi:10.1080/10407782.2013.733182.

[168] K. Ghasemi, M. Siavashi, MHD nanofluid free convection and entropy generation in porous enclosures with different conductivity ratios, J. Magn. Magn. Mater. 442 (2017) 474-490. doi:10.1016/j.jmmm.2017.07.028.

[169] G.C. Bourantas, V.C. Loukopoulos, MHD natural-convection flow in an inclined square enclosure filled with a micropolar-nanofluid, Int. J. Heat Mass Transf. 79 (2014) 930-944. doi:10.1016/j.ijheatmasstransfer.2014.08.075.

[170] M.A. Mansour, S. Siddiqa, R.S.R. Gorla, A.M. Rashad, Effects of heat source and sink on entropy generation and MHD natural convection of $\mathrm{Al} 2 \mathrm{O} 3-\mathrm{Cu} /$ water hybrid nanofluid filled with square porous cavity, Therm. Sci. Eng. Prog. 6 (2018) 57-71. doi:10.1016/j.tsep.2017.10.014.

Figure 1. Trends of articles on thermo-convection of nanofluids in non-square cavities (Scopus ${ }^{\circledR}$, December 26, 2019) 
Figure 2. Trends of articles on thermomagnetic convection of nanofluids in cavities (Scopus ${ }^{\circledR}$, December 26, 2019)

Table 1: MHD natural convection in non-square cavities (Numerical methods)

\begin{tabular}{lllll}
\hline Authors & Approach & Geometry & Nanofluid & Magn \\
\hline Benos et al. [153] & Asymptotic expansions. & Shallow rectangular cavity (steady and 2-D). & SWCNT-water. & Unifor \\
Benos and Sarris [152] & Asymptotic expansions. & Shallow rectangular (steady and 2-D). & Cu-water. & Unifor \\
\hline
\end{tabular}

Table 2: MHD natural convection in non-square cavities (Analytical methods)

\begin{tabular}{lllll}
\hline Authors & Approach & Geometry & Nanofluid & Magn \\
\hline Benos et al. [153] & Asymptotic expansions. & Shallow rectangular cavity (steady and 2-D). & SWCNT-water. & Unifor \\
Benos and Sarris [152] & Asymptotic expansions. & Shallow rectangular (steady and 2-D). & Cu-water. & Unifor \\
\hline
\end{tabular}

Table 3: Special cases of MHD natural convection in non-square cavities

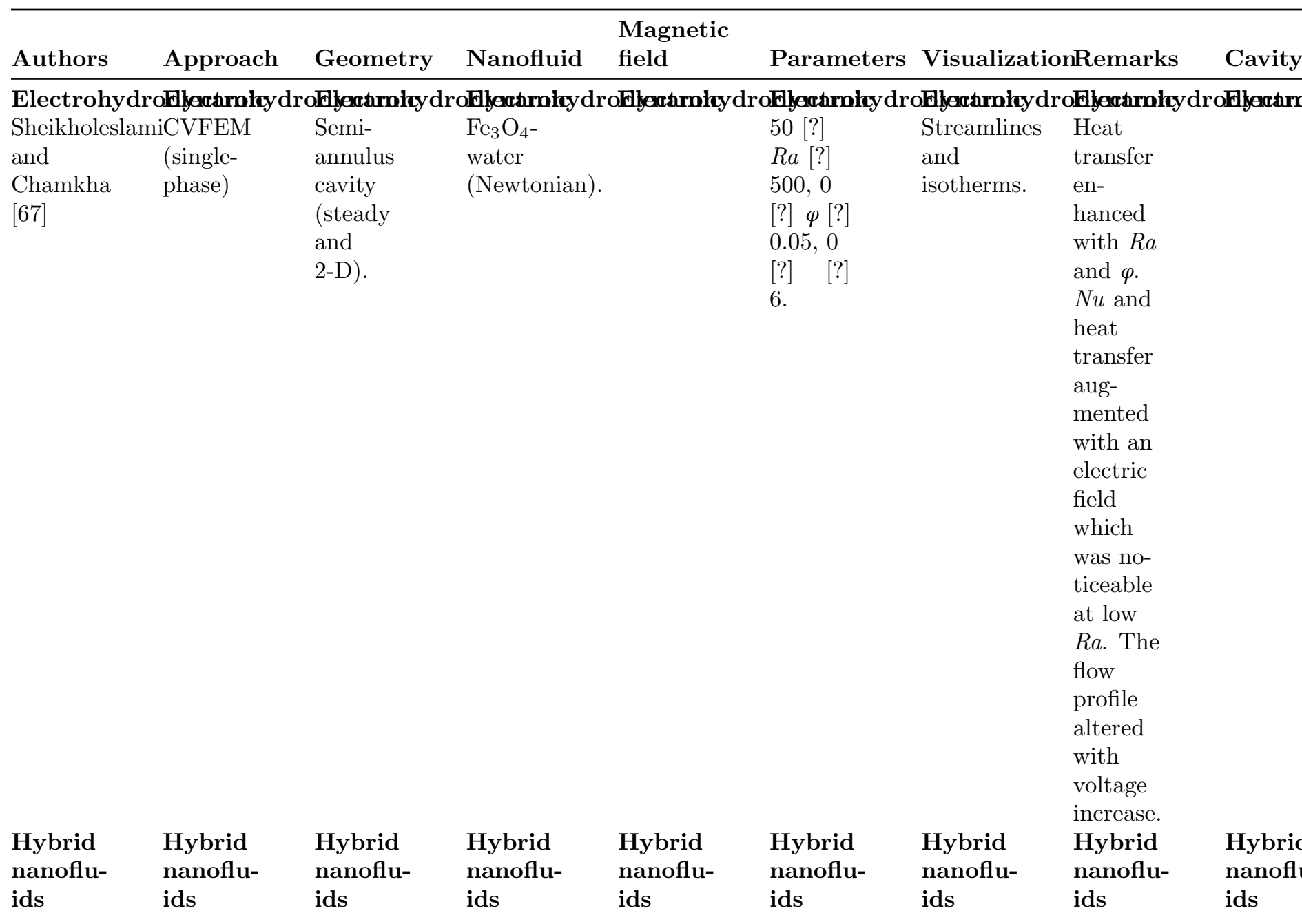




\begin{tabular}{|c|c|c|c|c|c|c|c|c|}
\hline Authors & Approach & Geometry & Nanofluid & $\begin{array}{l}\text { Magnetic } \\
\text { field }\end{array}$ & Parameters & \multicolumn{2}{|c|}{ VisualizationRemarks } & Cavity \\
\hline $\begin{array}{l}\text { Ashorynejad } \\
\text { and } \\
\text { Shahriari } \\
{[154]}\end{array}$ & $\begin{array}{l}\text { LBM } \\
\text { (single- } \\
\text { phase). }\end{array}$ & $\begin{array}{l}\text { Wavy- } \\
\text { walled open } \\
\text { cavity with } \\
\text { sinusoidal } \\
\text { heating } \\
\text { (steady and } \\
2-D) .\end{array}$ & $\begin{array}{l}\mathrm{Al}_{2} \mathrm{O}_{3^{-}} \\
\mathrm{Cu} / \text { water. }\end{array}$ & $\begin{array}{l}\text { Uniform } \\
\text { magnetic } \\
\text { field } \\
\text { (axially } \\
\text { applied). }\end{array}$ & $\begin{array}{l}10^{3}[?] \quad R a \\
{[?] 10^{5}, 0} \\
{[?] H a[?]} \\
90,0[?] \varphi \\
{[?] 0.04,0} \\
{[?] \Psi[?]} \\
3 \pi / 4 .\end{array}$ & $\begin{array}{l}\text { Streamlines } \\
\text { and } \\
\text { isotherms. }\end{array}$ & $\begin{array}{l}N u \\
\text { attenuated } \\
\text { with } H a \\
\text { and } \\
\text { enhanced } \\
\text { with } R a \\
\text { and } \varphi \text {. At } \\
R a=10^{5} \text {, } \\
N u \\
\text { enhanced } \\
\text { with } \varphi \text { and } \\
\psi \text {. Heat } \\
\text { transfer } \\
\text { was } \\
\text { maximum } \\
\text { at } H a=90 \\
\text { and } \\
\text { minimum } \\
\text { at } H a=30 \text {. }\end{array}$ & \\
\hline $\begin{array}{l}\text { Rashad et } \\
\text { al. [155] }\end{array}$ & $\begin{array}{l}\text { FEM } \\
\text { (single- } \\
\text { phase). }\end{array}$ & $\begin{array}{l}\text { Triangular } \\
\text { cavity with } \\
\text { constant } \\
\text { heat flux } \\
\text { bottom } \\
\text { heating } \\
\text { (steady and } \\
\text { 2-D). }\end{array}$ & $\begin{array}{l}\mathrm{Cu}^{-} \\
\mathrm{Al}_{2} \mathrm{O}_{3} / \text { water. }\end{array}$ & $\begin{array}{l}\text { Constant } \\
\text { and hori- } \\
\text { zontally } \\
\text { applied. }\end{array}$ & $\begin{array}{l}10^{2}[?] R a \\
{[?] 10^{6}, 0} \\
{[?] H a[?]} \\
100,0[?] \varphi \\
{[?] 0.2,0[?]} \\
Q[?] 6,0.2 \\
{[?] B[?]} \\
0.8,0.3[?] \\
D[?] 0.7 .\end{array}$ & $\begin{array}{l}\text { Streamlines } \\
\text { and } \\
\text { isotherms. }\end{array}$ & $\begin{array}{l}\text { Heat } \\
\text { transfer } \\
\text { augmented } \\
\text { with } \\
\text { increase of } \\
D \text { and } R a, \\
\text { and } \\
\text { reduction } \\
\text { of } B \text { but } \\
\text { declined } \\
\text { with rise of } \\
Q \text { and } H a \text {. } \\
\text { Increasing } \\
\varphi \text { was } \\
\text { found to be } \\
\text { obvious } \\
\text { when } R a \\
\text { was low, } \\
H a \text { was } \\
\text { high and, } \\
\text { when } D \\
\text { and } B \\
\text { increased. }\end{array}$ & \\
\hline
\end{tabular}




\begin{tabular}{|c|c|c|c|c|c|c|c|c|}
\hline Authors & Approach & Geometry & Nanofluid & $\begin{array}{l}\text { Magnetic } \\
\text { field }\end{array}$ & Parameters & \multicolumn{2}{|c|}{ VisualizationRemarks } & Cavity \\
\hline $\begin{array}{l}\text { Mehryan et } \\
\text { al. [156] }\end{array}$ & $\begin{array}{l}\text { FEM } \\
\text { (two-phase) }\end{array}$ & $\begin{array}{l}\text { Inverted } \\
\text { T-shaped } \\
\text { cavity } \\
\text { (steady and } \\
\text { 2-D). }\end{array}$ & $\begin{array}{l}\text { MWCNT- } \\
\mathrm{Fe}_{3} \mathrm{O}_{4} / \text { water. }\end{array}$ & $\begin{array}{l}\text { Inclined } \\
\text { and } \\
\text { uniform. }\end{array}$ & $\begin{array}{l}0.7[?] \xi_{\rho} \\
{[?] 1.4,0} \\
{[?] K_{r}[?]} \\
10,0[?] \varphi \\
{[?] 0.3,0} \\
{[?] \gamma[?]} \\
180^{\circ}, 0.2[?] \\
H_{r}[?] 0.8, \\
0[?] \delta o[?] \\
1, H a=20 \\
R a=10^{5}, \\
D a=10^{-2} \\
D a_{r}=1\end{array}$ & $\begin{array}{l}\text { Streamlines } \\
\text { and } \\
\text { isotherms. }\end{array}$ & $\begin{array}{l}\text { Heat } \\
\text { transfer } \\
\text { enhanced } \\
\text { with } \\
\text { increment } \\
\text { of } e_{\mathrm{r}} \text { and } \\
\mathrm{K}_{\mathrm{r}} \text { and } \\
\text { reduction } \\
\text { of } \delta_{0} \text { and } \\
\mathrm{H}_{\mathrm{r}} . N u \\
\text { enhanced } \\
\text { with } \delta_{0} \text { and } \\
\mathrm{K}_{\mathrm{r}} \text {. Highest } \\
N u_{\text {ave }} \text { was } \\
\text { observed at } \\
\gamma=140^{\circ} \\
\text { and when } \\
\delta_{0}=0 \text { for } \\
\text { all } \gamma \text { values. }\end{array}$ & \\
\hline
\end{tabular}

Table 4. Correlations for MHD natural convection of non-square cavities

\begin{tabular}{|c|c|}
\hline Correlations & Reference \\
\hline $\mathrm{Nu}_{\text {ave }}=5.9733-0.0878 H a-0.7074 \theta-0.4056 \theta^{2}$ & Mamourian et al. [164] \\
\hline$S_{\mathrm{gen}}=6.402-0.243 H a-2.103 \theta-3.164 \theta^{2}$ & Mamourian et al. [164] \\
\hline $\begin{array}{l}\mathrm{Nu}_{\text {ave }}=5.96-0.35 D a^{*}-2.9 \log (\mathrm{Ra})+0.77 \mathrm{Ha}^{*}+ \\
0.23 D a^{*} \log (\mathrm{Ra})-0.05 D a^{*} \mathrm{Ha}^{*}-0.17 \log (\mathrm{Ra}) \mathrm{Ha}^{*} \\
-0.22\left(\mathrm{Da}^{*}\right)^{2}+0.5(\log (\mathrm{Ra}))^{2}-0.06\left(\mathrm{Ha}^{*}\right)^{2}\end{array}$ & Sheikholeslami [140] \\
\hline $\begin{array}{l}\mathrm{Nu}_{\text {ave }}=27.97-3.84 R d-13.2 \log (\mathrm{Ra})-0.6 \mathrm{Da}^{*}+ \\
1.5 \mathrm{Ha}^{*}+2.32 R d \log (\mathrm{Ra})+0.5 R d D a^{*}-0.79 R d \mathrm{Ha}^{*}+ \\
0.25 \mathrm{Da}^{*} \log (\mathrm{Ra})-0.4 \mathrm{Ha}^{*} \log (\mathrm{Ra})-0.64 D a^{*} \mathrm{Ha}^{*}- \\
3.11 \mathrm{Rd}^{2}+1.72(\log (\mathrm{Ra}))^{2}+0.33\left(\mathrm{Da}^{*}\right)^{2}- \\
0.22\left(\mathrm{Ha}^{*}\right)^{2}\end{array}$ & Sheikholeslami and Shamlooei [83] \\
\hline $\begin{array}{l}\mathrm{Nu}_{\mathrm{ave}}=6.86-2.5 \log (\mathrm{Ra})+1.5 R d+0.05 H a+ \\
3.34 \varphi+0.69 \log (\mathrm{Ra}) \mathrm{Rd}-0.04 \log (\mathrm{Ra}) \mathrm{Ha}+ \\
2.38 \log (\mathrm{Ra}) \varphi+33 \times 10^{-3} R d H a+9.5 R d \varphi- \\
0.11 H a \varphi+0.44(\log (\mathrm{Ra}))^{2}+2.4 \mathrm{Rd}^{2}+0.5 \times \\
10^{-4} \mathrm{Ha}^{2}+102.3 \varphi^{2}\end{array}$ & Sheikholeslami and Shamlooei [137] \\
\hline $\begin{array}{l}\mathrm{Nu}_{\text {ave }}=18.8-5.4 R d-8.1 \log (\mathrm{Ra})-1.2 \mathrm{Ha}^{*}+ \\
1.68 R d \log (\mathrm{Ra})-0.2 R d \mathrm{Ha}^{*}- \\
0.32 \mathrm{Ha}^{*} \log (\mathrm{Ra})+1.6 \mathrm{Rd}^{2} \\
+1.07(\log (\mathrm{Ra}))^{2}-0.15\left(\mathrm{Ha}^{*}\right)^{2}\end{array}$ & Sheikholeslami and Rokni [143] \\
\hline $\begin{array}{l}\mathrm{Nu}_{\text {ave }}= \\
9.94-0.22 \theta-4.44 R d-4.76 \log (\mathrm{Ra})+0.98 \mathrm{Ha}^{*}+ \\
0.4 \theta R d-0.06 \theta \log (\mathrm{Ra})-0.06 \theta \mathrm{Ha}^{*}+ \\
1.69 \log (\mathrm{Ra}) R d-0.351 \log (\mathrm{Ra}) \mathrm{Ha}^{*}-0.25 R d \mathrm{Ha}^{*}- \\
0.23 \theta^{2}+0.72(\log (\mathrm{Ra}))^{2}+1.49 \mathrm{Rd}^{2}-0.06\left(\mathrm{Ha}^{*}\right)^{2}\end{array}$ & Sheikholeslami [144] \\
\hline
\end{tabular}




\begin{tabular}{l}
\hline Correlations \\
\hline $\mathrm{Nu}_{\text {ave }}=6.9-1.12 \log (\mathrm{Ra})+29.17 \varphi+9.4 \times$ \\
$10^{-3} \mathrm{Ha}-1.21 \varphi \log (\mathrm{Ra})-4 \times 10^{-3} \mathrm{Halog}(\mathrm{Ra})-$ \\
$9.1 \times 10^{-3} \varphi \mathrm{Ha}+0.17(\log (\mathrm{Ra}))^{2}+10.76 \varphi^{2}+$ \\
$1.7 \times 10^{-4} \mathrm{Ha}^{2}$ \\
$\mathrm{Nu}_{\text {ave }}=$ \\
$2.23+0.06 \theta+1.3 \times 10^{-3} \mathrm{Ra}-0.22 \mathrm{Ha}+1.35 \times$ \\
$10^{-4} \theta \mathrm{Ra}-6.36 \times 10^{-3} \theta H a-9.06 \times 10^{-5} \mathrm{RaHa}-$ \\
$4.7 \times 10^{-3} \theta^{2}+3.55 \times 10^{-7} \mathrm{Ra}^{2}+0.012 \mathrm{Ha}^{2}$ \\
$\mathrm{Nu}_{\text {ave }}=12.12-2.27 r_{\text {in }}-7.27(\log (\mathrm{Ra}))-1.29 \varphi+$ \\
$0.16 H a+1.5 r_{\text {in }}(\log (\mathrm{Ra}))+0.6 r_{\text {in }} \varphi-0.04 r_{\text {in }} \mathrm{Ha}+$ \\
$0.78(\log (\mathrm{Ra})) \varphi-0.04(\log (\mathrm{Ra})) H a-0.02 \varphi \mathrm{Ha}+$ \\
$2 r_{\text {in }}{ }^{2}+1.04(\log (\mathrm{Ra}))^{2}+14.05 \varphi^{2}+1.5 \times 10^{-5} \mathrm{Ha}{ }^{2}$ \\
$\mathrm{Nu}_{\text {ave }}=2.17+3.7 \times 10^{-4} \mathrm{Ra}+12.85 r_{\text {in }}+13.42 \varphi-$ \\
$0.018 H a-4.5 \times 10^{-4} \mathrm{Rar}_{\text {in }}-3.82 \times 10^{-4} \mathrm{Ra \varphi}-$ \\
$1.45 \times 10^{-5} \mathrm{RaHa}+3.45 r_{\text {in }} \varphi+0.04 r_{\text {in }} H a+$ \\
$0.036 \varphi H a+5.6 \times 10^{-8} \mathrm{Ra}^{2}+9.44 r_{\text {in }}{ }^{2}+3.47 \times$ \\
$10^{-4} \mathrm{Ha}^{2}+27.9 \varphi^{2}+1.5 \times 10^{-5} \mathrm{Ha}^{2}$
\end{tabular}

$N u=a_{13}+a_{23} Y_{1}+a_{33} Y_{2}+a_{43} Y_{1}^{2}+a_{53} Y_{2}^{2}+a_{23} Y_{1} Y_{2}$

$Y_{1}=a_{11}+a_{21} \mathrm{Ha}^{*}+a_{31} \varphi+a_{41} \mathrm{Ha}^{* 2}+a_{51} \varphi^{2}+a_{61} \mathrm{Ha}^{*} \varphi$

$Y_{2}=a_{12}+a_{22} \operatorname{Ra}^{*}+a_{32} \varphi+a_{42} \operatorname{Ra}^{* 2}+a_{52} \varphi^{2}+a_{61} \operatorname{Ra}^{*} \varphi$

Where $\mathrm{Ha}^{*}=\frac{\mathrm{Ha}}{100}$ and $\mathrm{Ha}^{*}=\log (\mathrm{Ra})$

$\mathrm{Nu}_{\text {ave }}=-1.41+10.82 \varepsilon+0.43 a+2.3 \times 10^{-4} R a+$ $5.3 \times 10^{-3} \mathrm{Ha}+5.2 \varepsilon a+1.4 \times 10^{-4} \varepsilon \mathrm{Ra}-0.043 \varepsilon \mathrm{Ha}-$ $4.6 \times 10^{-4} a \mathrm{Ra}+6.05 \times 10^{-3} \mathrm{aHa}+1.6 \times 10^{-7} \mathrm{RaHa}-$ $11.9 \varepsilon^{2}-0.63 a^{2}+6.5 \times 10^{-7} \mathrm{Ra}^{2}+9.1 \times 10^{-4} \mathrm{Ha}^{2}$

$\mathrm{Nu}_{\text {ave }}=10.01-5.23 \log (\mathrm{Ra})-0.95 R d+0.06 \mathrm{Ha}-$ $5.4 \varphi+0.63 \log (\mathrm{Ra}) \mathrm{Rd}-0.025 \log (\mathrm{Ra}) \mathrm{Ha}+$ $2.05 \log (\mathrm{Ra}) \varphi-0.013 R d H a+4.6 R d \varphi-0.04 H a \varphi+$ $0.84(\log (\mathrm{Ra}))^{2}-0.37 \mathrm{Rd}^{2}+3.8 \times 10^{-4} \mathrm{Ha}^{2}+47.7 \varphi^{2}$ $\mathrm{Nu}_{\text {ave }}=22.3-3.13 R d-10.5 \log (\mathrm{Ra})-0.43 \mathrm{Da}^{*}+$ $1.03 \mathrm{Ha}^{*}+1.88 R d \log (\mathrm{Ra})+0.36 R d D a^{*}-$

$0.54 R d \mathrm{Ha}^{*}+0.19 \mathrm{Da}^{*} \log (\mathrm{Ra})-$ $0.28 \mathrm{Ha}^{*} \log (\mathrm{Ra})-0.52 \mathrm{Da}^{*} \mathrm{Ha}^{*}-$

$2.5 \mathrm{Rd}^{2}+1.37(\log (\mathrm{Ra}))^{2}+0.29\left(\mathrm{Da}^{*}\right)^{2}-0.17\left(\mathrm{Ha}^{*}\right)^{2}$

$\mathrm{Nu}_{\text {ave }}=6.47-1.53 \log (\mathrm{Ra})-0.52 \mathrm{Da}^{*}+$

$0.58 \mathrm{Ha}^{*}-0.18 \mathrm{Ha}^{*} \mathrm{Da}^{*}+1.08 \mathrm{Da}^{*} \log (\mathrm{Ra})-$

$0.18 \mathrm{Ha}^{*} \log (\mathrm{Ra})+0.25(\log (\mathrm{Ra}))^{2}-2.6\left(\mathrm{Da}^{*}\right)^{2}+$ $0.018\left(\mathrm{Ha}^{*}\right)^{2}$

$\mathrm{Nu}_{\text {ave }}=$

$0.98+5.5 \times 10^{-4} R a-0.016 \mathrm{~N}+0.51 \varphi-0.021 H a-$ $3.2 \times 10^{-6} \mathrm{RaN}-1.71 \times 10^{-5} \mathrm{Ra}-3.6 \mathrm{RaHa}+$ $0.15 N \varphi+3.15 \times 10^{-4} \mathrm{NHa}+0.016 \varphi \mathrm{Ha}+1.4 \times$ $10^{-7} \mathrm{Ra}^{2}+7.9 \times 10^{-3} N^{2}+46.5 \varphi^{2}+1.16 \times 10^{-3} \mathrm{Ha}^{2}$

\section{Reference}

Sheikholeslami and Rokni [86]

Sheikholeslami and Ganji [102]

Sheikholeslami and Ganji [139]

Sheikholeslami and Shehzad [103]

Sheikholeslami et al. [77]

Sheikholeslami et al. [89]

Sheikholeslami, Ganji [138]

Sheikholeslami et al. [100]

Sheikholeslami and Shehzad [165]

Sheikholeslami and Rokni [145] 


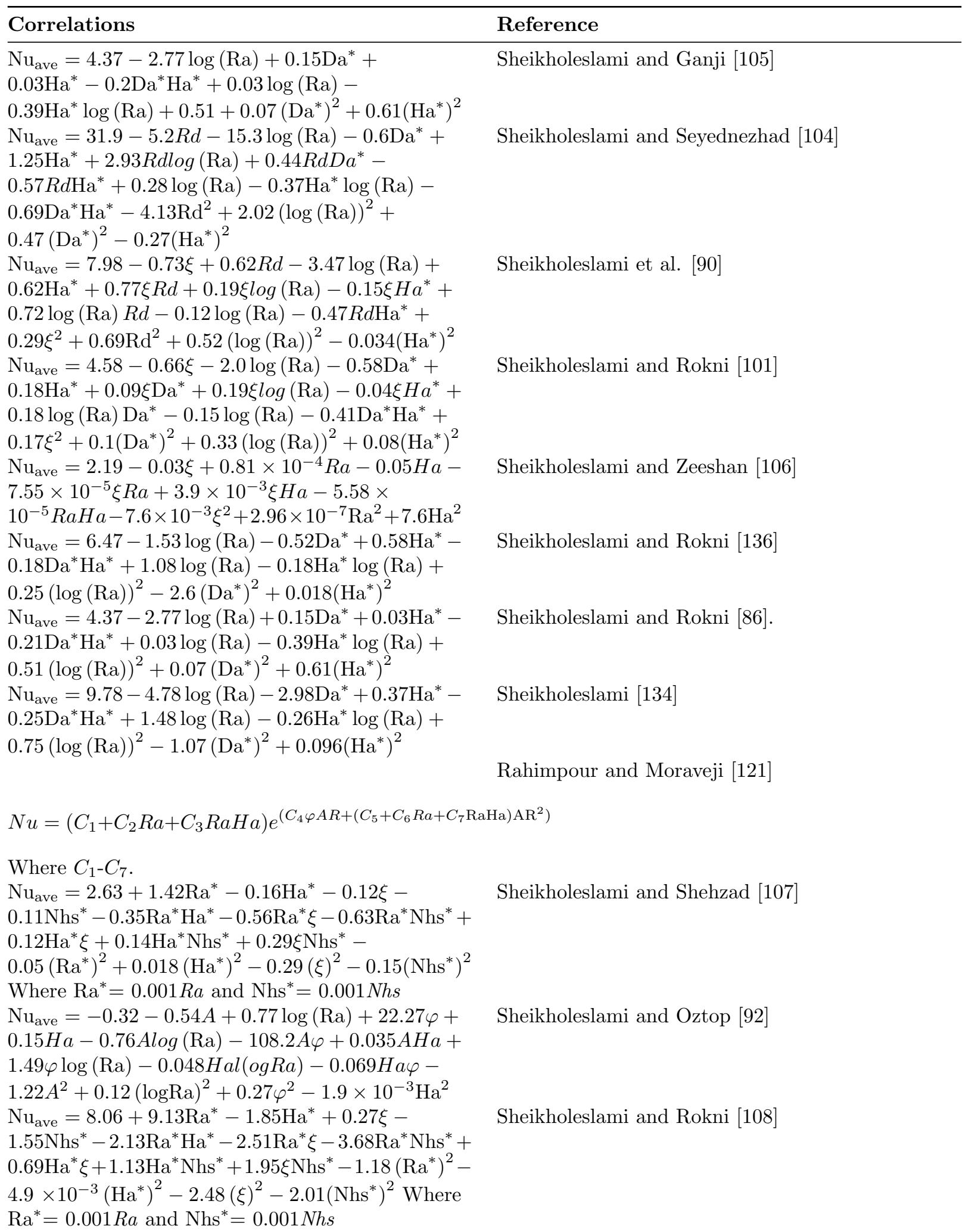




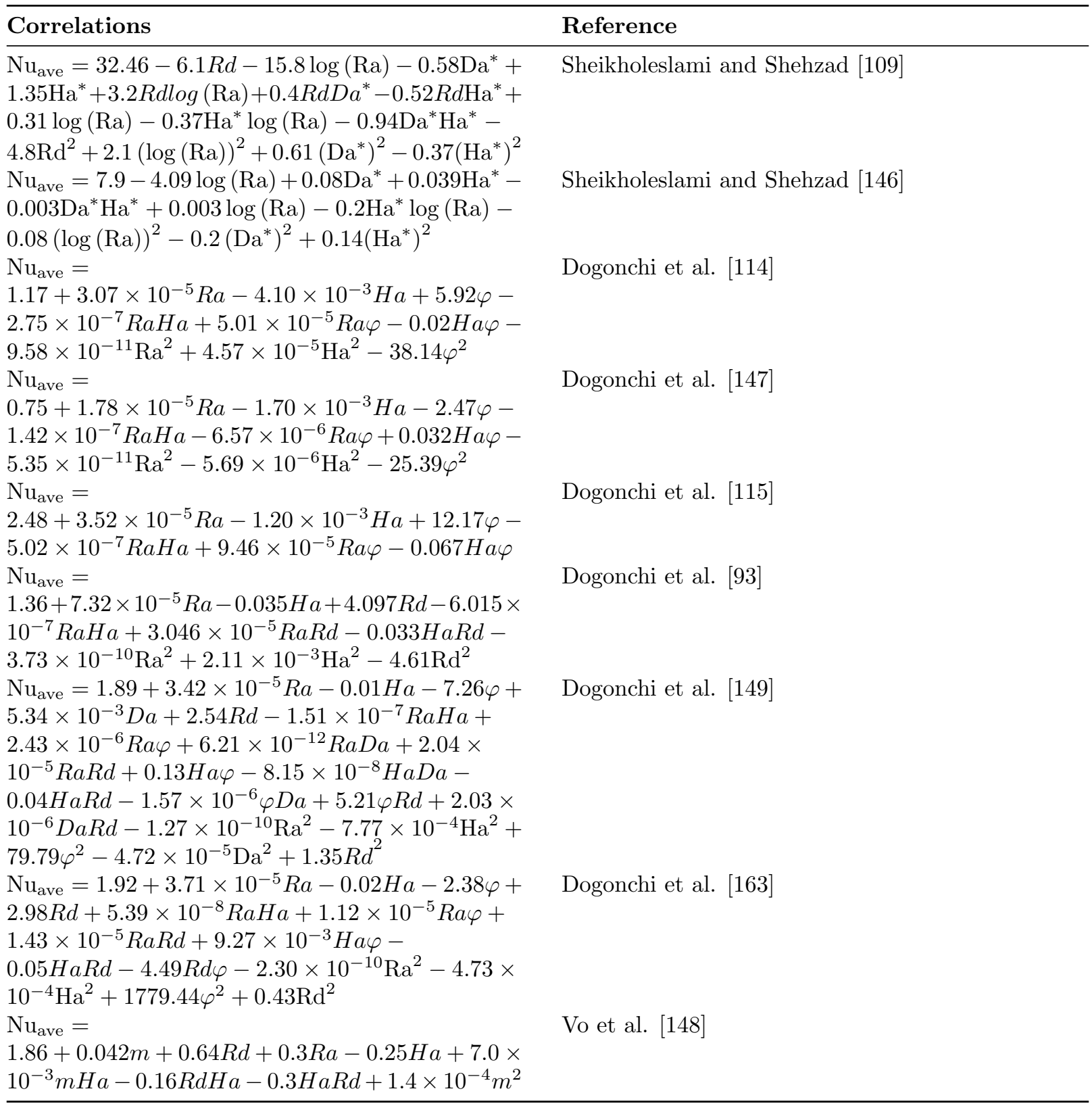

Where $\mathrm{Da}^{*}=0.01 \mathrm{Da}, \mathrm{Ha}^{*}=0.1 \mathrm{Ha}$

Table 5. Models/correlations utilised in numerical methods for MHD convection studies (nonsquare cavities)

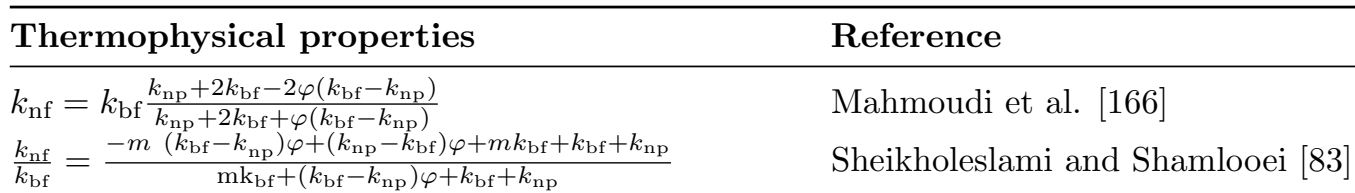




\section{Reference}

$$
k_{B}=5 \times 10^{4} \beta \varphi \rho_{\mathrm{bf}}\left(c_{p}\right)_{\mathrm{bf}} \sqrt{\frac{k_{\mathrm{bf}} T}{\rho_{\mathrm{np}} d_{\mathrm{np}}}} f(T, \varphi)
$$

\section{Mliki et al. [120]}

Where; $\beta=0.0137(100 \varphi)^{-0.8229}$ for $\varphi<1 \%$.

$\beta=0.0011(100 \varphi)^{-0.7272}$ for $\varphi[?] 1 \%$.

$f(T, \varphi)=(-6.04 \varphi+0.4705) T+(1722.3 \varphi-134.63)$

for $1 \%$ [?] $\varphi[?] 4 \%$.

$\frac{k_{\mathrm{nf}}}{k_{\mathrm{bf}}}=1+$

$64.7 \varphi^{0.746}\left(\frac{d_{\mathrm{bf}}}{d_{\mathrm{np}}}\right)^{0.369}\left(\frac{k_{\mathrm{np}}}{k_{\mathrm{bf}}}\right)^{0.7476} \operatorname{Pr}^{0.9955} \operatorname{Re}^{1.2321}$

Mahmoudi et al. [167]

$$
\frac{k_{\mathrm{nf}}}{k_{\mathrm{bf}}}=1+\frac{k_{\mathrm{np}} A_{\mathrm{np}}}{k_{\mathrm{bf}} A_{\mathrm{bf}}}+c k_{\mathrm{np}} \mathrm{Pe} \frac{A_{\mathrm{np}}}{k_{\mathrm{bf}} A_{\mathrm{bf}}}
$$

Mahmoudi et al. [123]

Where; $\mathrm{k}_{\mathrm{b}}=1.38 \times 10^{-23}, \mathrm{c}=3.6 \times 10^{4}$,

$\frac{A_{\mathrm{np}}}{A_{\mathrm{bf}}}=\frac{d_{\mathrm{bf}} \varphi}{d_{\mathrm{np}}(1-\varphi)}, d_{\mathrm{bf}}=\frac{u_{b} d_{\mathrm{np}}}{\alpha_{\mathrm{bf}}}, u_{b}=\frac{2 k_{b} T}{\pi \mu_{\mathrm{nf}} d_{\mathrm{np}}{ }^{2}}$

Ghasemi and Siavashi [168]

$$
\frac{k_{\mathrm{nf}}}{k_{\mathrm{bf}}}=1+4.4 \operatorname{Re}^{0.4} \stackrel{0.66}{\operatorname{Pr}}\left(\frac{T_{\mathrm{nf}}}{T_{\mathrm{fr}}}\right)^{10}\left(\frac{k_{\mathrm{np}}}{k_{\mathrm{bf}}}\right)^{0.03} \varphi^{0.66}
$$

Where $R e=\frac{\rho_{\mathrm{bf}} u_{b} d_{\mathrm{np}}}{\mu_{\mathrm{bf}}}$

$$
\begin{array}{ll}
k_{\mathrm{nf}}=k_{\mathrm{bf}}(1+7.47 \varphi) & \text { Bourantas et al. [169] } \\
k_{\mathrm{hnf}}= & \text { Mansour et al. [170] } \\
k_{\mathrm{bf}}\left(\frac{\left(\varphi_{n p 1} k_{n p 1}+\varphi_{n p 2} k_{n p 2}\right)}{\varphi}+2 k_{\mathrm{bf}}+2\left(\varphi_{n p 1} k_{n p 1}+\varphi_{n p 2} k_{n p 2}\right)-2 \varphi k_{\mathrm{bf}}\right) \times \\
\left(\frac{\left(\varphi_{n p 1} k_{n p 1}+\varphi_{n p 2} k_{n p 2}\right)}{\varphi}+2 k_{\mathrm{bf}}-\left(\varphi_{n p 1} k_{n p 1}+\varphi_{n p 2} k_{n p 2}\right)+\varphi k_{\mathrm{bf}}\right)^{-1}
\end{array}
$$$$
\text { Mansour et al. [170] }
$$

Where $\varphi=\varphi_{\nu \pi 1}+\varphi_{\nu \pi 2}$

$\mu_{\mathrm{nf}}=\frac{\mu_{\mathrm{bf}}}{(1-\varphi)^{2.5}}$

Mahmoudi et al. [123]

$\mu_{\mathrm{nf}}=$

Sheikholeslami and Shamlooei [83]

$\left(0.035 \mu_{o}^{2} H^{2}+3.1 \mu_{o} H-27889.4807 \varphi^{2}+4263.02 \varphi+316.0629\right) e^{-0.01 T}$

$\mu_{B}=5 \times 10^{4} \beta \varphi \rho_{\mathrm{bf}}\left(c_{p}\right)_{\mathrm{bf}} \sqrt{\frac{k_{\mathrm{bf}} T}{\rho_{\mathrm{np}} d_{\mathrm{np}}}} f(T, \varphi)$

$\mu_{\mathrm{nf}}=-0.6967+\left(\frac{15.937}{T}\right)+1.238 \varphi+\left(\frac{1356.14}{T^{2}}\right)-$ $0.259 \varphi^{2}-30.88\left(\frac{\varphi}{T}\right)-\left(\frac{19652.74}{T^{3}}\right)+0.01593 \varphi^{3}+$

$4.38206\left(\frac{\varphi^{2}}{T}\right)+147.573\left(\frac{\varphi}{T^{2}}\right)$

$\mu_{\mathrm{nf}}=\frac{\mu_{\mathrm{bf}}}{1-34.87\left(\frac{d_{\mathrm{np}}}{d_{\mathrm{bf}}}\right)^{-0.3} \varphi^{1.03}}$

$\mu_{\mathrm{nf}}=\mu_{\mathrm{bf}}\left(1+39.11 \varphi+533.9 \varphi^{2}\right)$

$\mu_{\mathrm{nf}}=-0.4491 \times 10^{-3}+\frac{2.8837 \times 10^{-2}}{T-273.15}+0.574 \times 10^{-3} \varphi-$

$0.1634 \times 10^{-3} \varphi^{2}+2.3053 \times 10^{-2}\left(\frac{\varphi}{T-273.15}\right)^{2}+$

$0.0132 \times 10^{-3} \varphi^{3}-2.354735\left(\frac{\varphi}{(T-273.15)^{3}}\right)+$

$2.3498 \times 10^{-2}\left(\frac{\varphi^{2}}{d_{\mathrm{np}}{ }^{2}}\right)-3.0185 \times 10^{-3}\left(\frac{\varphi^{3}}{d_{\mathrm{np}}{ }^{2}}\right)$

$\mu_{\mathrm{hnf}}=\frac{\mu_{\mathrm{bf}}}{\left(1-\left(\varphi_{n p 1}+\varphi_{n p 2}\right)\right)^{2.5}}$

$\frac{\sigma_{\mathrm{nf}}}{\sigma_{\mathrm{bf}}}=\frac{\sigma_{\mathrm{np}}+2 \sigma_{\mathrm{bf}}-2 \varphi\left(\sigma_{\mathrm{bf}}-\sigma_{\mathrm{np}}\right)}{\sigma_{\mathrm{np}}+2 \sigma_{\mathrm{bf}}+\varphi\left(\sigma_{\mathrm{bf}}-\sigma_{\mathrm{np}}\right)}$
Mliki et al. [120]

Mahmoudi et al. [167]

Ghasemi and Siavashi [168]

Bourantas et al. [169]

Astanina et al. [159]

Mansour et al. [170]

Mahmoudi et al. [167] 


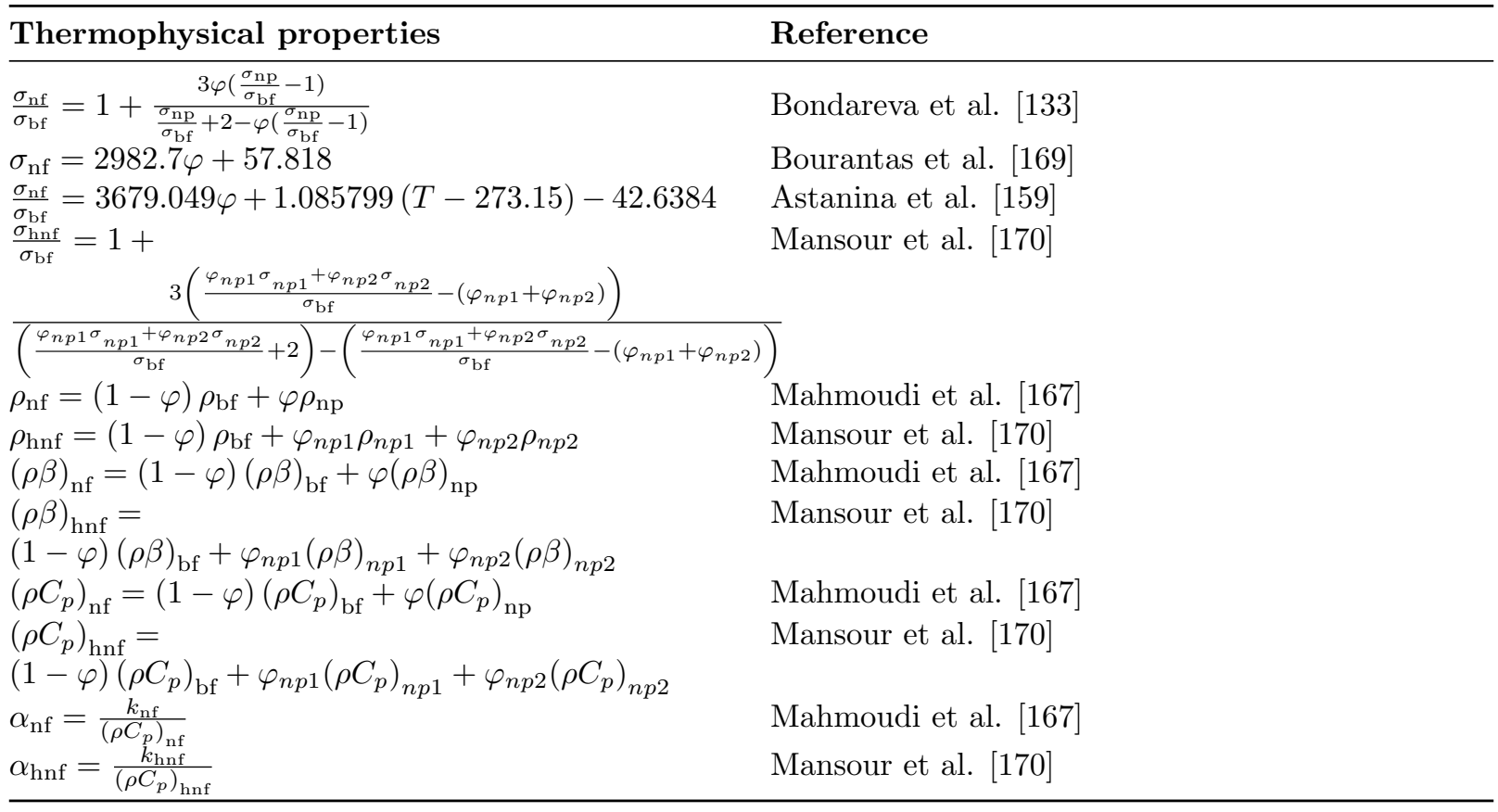

